\title{
EXECUTIVE COMPENSATION, STRATEGIC \\ COMPETITION, AND RELATIVE PERFORMANCE EVALUATION: THEORY AND EVIDENCE
}

Rajesh Aggarwal

Andrew A. Samwick

Working Paper 5648

\section{NATIONAL BUREAU OF ECONOMIC RESEARCH 1050 Massachusetts Avenue \\ Cambridge, MA 02138 July 1996}

We thank Sheri Aggarwal, Gary Engelhardt, Wayne Gray, Benjamin Hermalin, Dennis Logue, Jonathan Skinner, Matthew Slaughter, Sang-Seung Yi, and seminar participants at Dartmouth College for their helpful comments. We are grateful to John Fitzgerald for assistance with the ExecuComp dataset; Andrew Hait for assistance with the Census of Manufactures, and Ervin Tu for research assistance. All errors are our own. Any opinions expressed are those of the authors and not those of the National Bureau of Economic Research.

(C) 1996 by Rajesh Aggarwal and Andrew A. Samwick. All rights reserved. Short sections of text, not to exceed two paragraphs, may be quoted without explicit permission provided that full credit, including $(\mathcal{C}$ notice, is given to the source. 


\title{
EXECUTIVE COMPENSATION, STRATEGIC COMPETITION, AND RELATIVE PERFORMANCE EVALUATION: THEORY AND EVIDENCE
}

\begin{abstract}
We argue that strategic interactions between firms in an oligopoly can explain the puzzling lack of high-powered incentives in executive compensation contracts written by shareholders whose objective is to maximize the value of their shares. We derive the optimal compensation contracts for managers and demonstrate that the use of high-powered incentives will be limited by the need to soften product market competition. In particular, when managers can be compensated based on their own and their rivals' performance, we show that there will be an inverse relationship between the magnitude of high-powered incentives and the degree of competition in the industry. More competitive industries are characterized by weaker pay-performance incentives. Empirically, we find strong evidence of this inverse relationship in the compensation of executives in the United States. Our econometric results are not consistent with alternative theories of the effect of competition on executive compensation. We conclude that strategic considerations can preclude the use of highpowered incentives, in contrast to the predictions of the standard principal-agent model.
\end{abstract}

Rajesh Aggarwal Amos Tuck School Dartmouth College Hanover, NH 03755
Andrew A. Samwick

Department of Economics

Dartmouth College

Hanover, NH 03755

and NBER 


\section{Introduction}

The separation of ownership and control of large corporations is a central feature of modern economies. The largely unobserved choice of actions by a firm's managers can have a major impact on the wealth of its shareholders. The literature on principal-agent theory suggests that the primary means for the shareholders to ensure that managers take optimal actions is to tie managers' pay to the performance of their firms; that is, to provide high-powered incentives for managers to maximize the returns to shareholders. However, the empirical literature has not found evidence of high-powered incentives. Instead, the typical finding is a low pay-performance sensitivity, which seems to imply that shareholders are not providing managers with incentives to maximize the returns to shareholders.

In this paper, we argue that strategic interactions between firms in an oligopoly can explain the puzzling lack of high-powered incentives in executive compensation contracts written by shareholders whose objective is to maximize the value of their shares. We derive the optimal compensation contracts for managers and demonstrate that the use of high-powered incentives will be limited by the need to soften product market competition. In particular, when managers can be compensated based on their own and their rivals' performance, we show that there will be an inverse relationship between the magnitude of high-powered incentives and the degree of competition in the industry. More competitive industries are characterized by weaker pay-performance incentives. Empirically, we find strong evidence of this inverse relationship in the compensation of executives in the United States.

We conclude that strategic considerations can preclude the use of high-powered incentives, in contrast to the predictions of the standard principal-agent model. That model posits an economic trade-off between inducing the correct amount of unobservable effort by the agent and minimizing the amount of risk she is required to bear. In practice, that model 
predicts that managerial compensation will be correlated with the total return to shareholders, typically through ownership of shares of the firm's stock or grants of options on the firm's stock. In a seminal article, Jensen and Murphy (1990) test and reject this theoretical prediction, finding that the compensation of chief executive officers increased by only $\$ 3.25$ per $\$ 1,000$ increase in shareholder wealth. ${ }^{1} \quad$ They hypothesize that political forces (e.g., societal notions of fairness and equity) work to reduce the pay-performance sensitivity. ${ }^{2}$ This contrasts with our explanation that the pay-performance sensitivity is low because a high pay-performance sensitivity would induce overly aggressive behavior in the product markets.

Another prediction of the principal-agent model of executive compensation is that pay should be based not only on the returns to the firm's shareholders but on every variable that provides unique information about the actual action taken by the manager. ${ }^{3}$ A prominent example of such a variable is the profits of other firms in the same product market, leading to a compensation contract based on the relative performance of the manager compared to her rivals. The prediction from the relative performance evaluation model is that, other things equal, an executive will receive lower compensation if executives of rival firms deliver higher returns to their shareholders. In our model, the validity of this prediction depends on the nature of strategic competition. When the returns to attenuating competition are high, compensation contracts will not exhibit relative performance evaluation. When the returns to achieving product market leadership are high, contracts will have incentives that resemble 1 Later work by Haubrich (1994) has demonstrated that some parameterizations of the principal-agent model do allow for pay-performance sensitivites as low as the 0.003 found by Jensen and Murphy.

2 Finkelstein and Hambrick (1996) discuss the political forces that shape executive compensation in great detail.

3 This is the sufficient statistic result from Holmström's (1979) work on moral hazard. 
relative performance evaluation. The empirical literature on whether relative performance evaluation is an important source of managerial incentives finds mixed results. ${ }^{4}$ We do not find evidence in support of relative performance evaluation in our empirical work.

The lack of empirical confirmation is a consequence of the absence of strategic considerations from the standard principal-agent model, with or without relative performance evaluation. With few exceptions, the typical principal-agent model fails to recognize that the interaction between shareholders and managers occurs in an environment of strategic interactions between firms in imperfectly competitive markets. ${ }^{5}$ A model that considers compensation divorced from competition is incomplete. We show that when the optimal contract allows compensation to vary with own and industry performance, strategic interactions support relative performance pay-a negative relationship between executive compensation and industry performance-only when firm outputs are strategic substitutes, as in the standard Cournot model.

When outputs are strategic complements, as in the differentiated Bertrand model of price competition, relative performance pay lowers the shareholders' returns by encouraging more aggressive price setting by managers and is therefore not observed in equilibrium. In this case, the level of compensation under the optimal contract increases with both own and industry performance, softening competition and raising the returns to shareholders.

\footnotetext{
4 Jensen and Murphy find that relative performance is not an important source of managerial incentives. Gibbons and Murphy (1990) test more directly for relative performance pay and find that, holding constant the rate of return on a firm's common stock, a higher value-weighted industry rate of return lowers the growth of CEO pay.

5 The earliest papers that do recognize this interaction are Vickers (1987), Fershtman and Judd (1987), and Sklivas (1987). Vickers (1987) demonstrates that precommitment to managerial incentive contracts can facilitate collusion between rival firms. Fershtman and Judd (1987) and Sklivas (1987) derive similar results by allowing the compensation contract to include sales in addition to profits. Reitman (1993) demonstrates that the nonlinearity in profits introduced by a stock option improves the outcome for the shareholders relative to a contract that is linear in profits. See also Katz (1991), Hermalin (1992), and Fumas (1992).
} 
Furthermore, the differentiated Bertrand model generates the strong prediction that the optimal compensation contract is sensitive to the degree of substitutability in the firm's product market. In more competitive industries, managers are given weaker incentives to maximize returns to their own firms' shareholders and stronger incentives to maximize returns to all firms in the industry. Specifically, we show that the differentiated Bertrand model predicts that the ratio of the own-firm pay-performance sensitivity to the industry pay-performance sensitivity is a decreasing function of the level of competition in the industry.

We test our predictions by linking together two sources of data. We use industry concentration ratios from the Census of Manufactures to characterize product market competition and compensation data for executives of large corporations from the Standard and Poor's ExecuComp dataset. The prediction for the differentiated Bertrand model is confirmed empirically under a variety of econometric specifications. Our empirical results do not support the standard principal-agent model, the relative performance evaluation model, or the Cournot model that we derive.

The paper is organized as follows. In section 2 , we derive the form of optimal executive compensation contracts under differentiated Bertrand competition when contracts can vary with own and industry performance. In section 3, we repeat the analysis under the assumption that competition is Cournot. In section 4, we demonstrate that in our model the optimal contract is invariant to managerial risk aversion. In section 5 , we describe the data that we use for our empirical tests and, in section 6, present those findings. Section 7 discusses the implications of our empirical results for alternative theories of executive compensation. Section 8 concludes. 


\section{Bertrand Competition}

We consider the following contracting model. There are two firms in an industry, 1 and 2, who engage in differentiated Bertrand competition. The model has two stages. At stage 1 , the owners of the firms write contracts with the managers, and at stage 2 the managers engage in differentiated Bertrand competition. ${ }^{6}$ We assume a manager's action choice at stage 2 is unobservable. Profits, or statistics for profits such as returns to shareholders, are observable, so contracts can be made contingent only on profits. Firms face symmetric demand functions given by:

$$
\begin{aligned}
& D_{1}\left(p_{1}, p_{2}\right)=A-b p_{1}+a p_{2}+\varepsilon \\
& D_{2}\left(p_{1}, p_{2}\right)=A-b p_{2}+a p_{1}+\varepsilon
\end{aligned}
$$

$\varepsilon$ is a mean zero shock to demand with variance $\sigma^{2}$. Therefore, prices cannot be perfectly inferred from profits. We assume that $b>a$. That is, the manager's action choice has a greater impact on the demand for her own product than does her rival's action. We assume linear demands and two firms because this specification yields straightforward comparative statics across product markets. The results of our model will generalize to industries with more than two firms and to nonlinear demand functions so long as $\frac{\partial D_{i}}{\partial p_{i}}<0, \frac{\partial D_{i}}{\partial p_{j}}>0$, and $\left|\frac{\partial D_{i}}{\partial p_{i}}\right|>\frac{\partial D_{i}}{\partial p_{j}}$.

At stage 1 , if contracts are written contingent solely on own firm profits, we get the standard differentiated Bertrand result. A contract that is increasing in own profits will induce the manager to choose the profit maximizing price. If marginal cost is given by c, we have the following program for the manager:

$$
\max _{p_{1}}\left(p_{1}-c\right)\left(A-b p_{1}+a p_{2}+\varepsilon\right)
$$

${ }_{6}$ Our derivation will apply to any model with strategic complements. 
and symmetrically for the manager for firm 2. Firm 1's reaction function is:

$$
p_{1}=\frac{A+b c+a p_{2}+\varepsilon}{2 b}
$$

and the profit maximizing choice for $p_{1}$ is:

$$
p_{1}=\frac{A+b c+\varepsilon}{2 b-a}
$$

Symmetric equations hold for firm 2. We can then calculate profits under this standard differentiated Bertrand model (which we do in the proof of Proposition 1).

The question we wish to ask is, can the standard contract be improved upon? Would the owner of firm 1 raise her profits by offering the manager a contract contingent upon the rival firm's profits as well as the own firm's profits? Suppose the following contract is offered to the manager of firm 1 :

$$
w_{1}=k_{1}+\alpha \pi_{1}+\beta \pi_{2}
$$

where

$$
\pi_{i}=\left(p_{i}-c\right)\left(A-b p_{i}+a p_{j}+\varepsilon\right)
$$

In this model, the owner of firm 1 chooses the contract, the contract is revealed to both managers, and then the managers choose prices. We assume that the manager of firm 1 has a reservation wage $w_{1}^{\prime}$ and that the managerial labor market is competitive. Therefore, the manager of firm 1 is always held to her reservation wage. The first period program for the owner of firm 1 is:

$$
\max _{\boldsymbol{\alpha}, \beta} E\left[\pi_{1}\right]-w_{1}
$$

$$
\begin{array}{ll}
\text { s.t. } & w_{1} \geq w_{1}^{\prime} \text { and } \\
& p_{1}^{\prime} \in \arg \max _{p_{1}} w_{1} .
\end{array}
$$


The first constraint is the manager's individual rationality constraint, which will always bind through the choice of $k_{1}$, the fixed payment in the managerial incentive contract. The second constraint ensures that the manager's second period action choice is optimal given the first period contract.

We start by analyzing the second period action choice of firm 1's manager in the differentiated Bertrand game. Explicitly, the manager's problem is:

$$
\max _{p_{1}} \alpha\left(p_{1}-c\right)\left(A-b p_{1}+a p_{2}+\varepsilon\right)+\beta\left(p_{2}-c\right)\left(A-b p_{2}+a p_{1}+\varepsilon\right)
$$

Firm 1's reaction function is

$$
p_{1}=\frac{A+b c+a p_{2}+\varepsilon}{2 b}+\frac{\beta a p_{2}-\beta a c}{2 \alpha b}
$$

Firm 2's manager's second period action choice is given by the standard Bertrand problem:

$$
\max _{p_{2}}\left(p_{2}-c\right)\left(A-b p_{2}+a p_{1}+\varepsilon\right)
$$

Firm 2's reaction function is:

$$
p_{2}=\frac{A+b c+a p_{1}+\varepsilon}{2 b}
$$

Jointly solving both gives prices as a function of firm 1's first period contract.

$$
\begin{aligned}
& p_{1}^{\prime}=\frac{(A+\varepsilon)(\alpha a+2 b \alpha+\beta a)+b c(2 b \alpha+\alpha a-\beta a)}{4 \alpha b^{2}-\alpha a^{2}-\beta a^{2}} \\
& p_{2}^{\prime}=\frac{\alpha(A+\varepsilon)(2 b+a)+c\left(2 \alpha b^{2}-\beta a^{2}+\alpha a b\right)}{4 \alpha b^{2}-\alpha a^{2}-\beta a^{2}}
\end{aligned}
$$

Substituting these price choices back into the owner's first period problem and holding the manager to her reservation wage yields the following program:

$$
\max _{\alpha, \beta} E\left[\left(p_{1}^{\prime}-c\right)\left(A-b p_{1}^{\prime}+a p_{2}^{\prime}+\varepsilon\right)\right]-w_{1}^{\prime}
$$


There is a continuum of optimal contracts given by:

$$
\alpha^{\prime}=x \frac{4 b^{2}+2 a b-a^{2}}{(a+2 b) a}, \quad \beta^{\prime}=x, \quad x \in \Re^{+} .
$$

which generate expected prices of:

$$
\begin{aligned}
& E\left[p_{1}^{\prime}\right]=\frac{1}{2} \frac{c\left(a b+2 b^{2}-a^{2}\right)+A(a+2 b)}{2 b^{2}-a^{2}} \\
& E\left[p_{2}^{\prime}\right]=\frac{1}{4} \frac{-c a^{3}-a^{2} A-b a^{2} c+2 a b A+2 a b^{2} c+4 b^{2} A+4 b^{3} c}{b\left(2 b^{2}-a^{2}\right)}
\end{aligned}
$$

We first establish that firm 1's expected prices and profits are higher under this contractual arrangement than under standard differentiated Bertrand competition. All proofs of propositions are in the appendix.

Proposition 1 If $E\left[p_{1}\right]>c$, then $E\left[p_{1}^{\prime}\right]>E\left[p_{1}\right], E\left[\pi_{1}^{\prime}\right]>E\left[\pi_{1}\right], E\left[p_{2}^{\prime}\right]>E\left[p_{2}\right]$ and $E\left[\pi_{2}^{\prime}\right]>$ $E\left[\pi_{2}\right]$.

This establishes that firm 1 would like to write a contract based on both firms' profits and that firm 2 benefits when firm 1 does so. Next we establish that firm 2 would like to offer its manager an analogous contract. We continue to consider linear contracts of the following form:

$$
\begin{aligned}
& w_{1}=k_{1}+\alpha \pi_{1}+\beta \pi_{2} \\
& w_{2}=k_{2}+\gamma \pi_{2}+\delta \pi_{1} .
\end{aligned}
$$

We put no restrictions on $\alpha, \beta, \delta$ or $\gamma$; they could be greater than 1 or less than 0 . We assume each manager has a reservation wage, $w_{1}^{\prime}$ and $w_{2}^{\prime}$, and that the managerial labor market is competitive. Therefore, the k's, which are constants, are chosen so that the managers are always held to their reservation wages. The first period program for the owner of firm 1 is:

$$
\begin{array}{ll} 
& \max _{\alpha_{1} \beta} E\left[\pi_{1}\right]-w_{1} \\
\text { s.t. } \quad w_{1} \geq w_{1}^{\prime} \text { and } \\
p_{1}^{*} \in \arg \max _{p_{1}} w_{1}
\end{array}
$$


where the constraints are as given in program 7 .

We start by analyzing the manager's second period action choice in the differentiated Bertrand game, which is the same problem we analyzed before for firm 1 . As in program 8 , the manager's problem is:

$$
\max _{p_{1}} \alpha\left(p_{1}-c\right)\left(A-b p_{1}+a p_{2}+\varepsilon\right)+\beta\left(p_{2}-c\right)\left(A-b p_{2}+a p_{1}+\varepsilon\right)
$$

As above, firm 1's reaction function is

$$
p_{1}=\frac{A+b c+a p_{2}+\varepsilon}{2 b}+\frac{\beta a p_{2}-\beta a c}{2 \alpha b}
$$

and a symmetric equation holds for firm 2. The optimal price levels as functions of $\alpha, \beta, \delta$ and $\gamma$ are:

$$
\begin{aligned}
p_{1}^{*} & =\frac{-\gamma(A+\varepsilon)(\alpha a+2 b \alpha+\beta a)-\gamma b c(2 b \alpha+\alpha a-\beta a)+a^{2} c \delta(\alpha+\beta)}{-4 \gamma b^{2} \alpha+\alpha a^{2} \gamma+\alpha a^{2} \delta+\beta a^{2} \gamma+\beta a^{2} \delta} \\
p_{2}^{*} & =\frac{-\alpha(A+\varepsilon)(a \delta+2 \gamma b+a \gamma)-\alpha b c(2 \gamma b-a \delta+a \gamma)+\beta a^{2} c(\delta+\gamma)}{-4 \gamma b^{2} \alpha+\alpha a^{2} \gamma+\alpha a^{2} \delta+\beta a^{2} \gamma+\beta a^{2} \delta}
\end{aligned}
$$

Substituting the price choices back into the owners' first period problems and holding the managers to their reservation wages yields the following program for firm 1 :

$$
\max _{\alpha, \beta} E\left[\left(p_{1}^{*}-c\right)\left(A-b p_{1}^{*}+a p_{2}^{*}+\varepsilon\right)\right]-w_{1}^{\prime} .
$$

A similar program holds for firm 2. Jointly solving both gives the continuum of optimal contracts for each firm's manager, which is:

$$
\begin{aligned}
& \alpha^{*}=\frac{2 b-a}{a} y, \quad \beta^{*}=y, y \in \Re^{+} . \\
& \gamma^{*}=\frac{2 b-a}{a} z, \quad \delta^{*}=z, \quad z \in \Re^{+} .
\end{aligned}
$$

We can now solve for the symmetric equilibrium prices, $p_{i}^{*}$ : 


$$
p_{i}^{*}=\frac{A(2 b-a)+c(b-a)(2 b+a)+(2 b-a) \varepsilon}{4 b(b-a)} .
$$

Proposition 2 compares expected prices and profits in the case where both managers can be compensated on own and rival-firm profits to the case where only firm 1's manager can be compensated on own and rival-firm profits and to the case where both managers are compensated strictly on their own-firm profits.

Proposition 2 If $E\left[p_{i}\right]>c$, then $E\left[p_{2}^{*}\right]>E\left[p_{2}^{\prime}\right]>E\left[p_{2}\right], E\left[\pi_{2}^{*}\right]>E\left[\pi_{2}^{\prime}\right]>E\left[\pi_{2}\right], \quad E[$ $\left.p_{1}^{*}\right]>E\left[p_{1}^{\prime}\right]>E\left[p_{1}\right]$, and $E\left[\pi_{1}^{*}\right]>E\left[\pi_{1}^{\prime}\right]>E\left[\pi_{1}\right]$. Further, if $\beta^{\prime}=\beta^{*}$, then $\alpha^{\prime}>\alpha^{*}$.

Figure 1 depicts the shift in equilibrium as we move from standard differentiated Bertrand competition to competition characterized by compensation contracts based on own and rivalfirm profits. The upward sloping lines labelled $\mathrm{p}_{1}$ and $\mathrm{p}_{2}$ are firm 1 and firm 2's reaction functions under standard differentiated Bertrand competition. The lines labelled $\mathrm{p}_{1}^{\prime}$ and $\mathrm{p}_{2}^{\prime}$ are the reactions functions when managers can be compensated on both own and rival-firm profits. In the new equilibrium, prices $\left(p_{1}^{*}, p_{2}^{*}\right)$ are higher relative to standard differentiated Bertrand competition.

Allowing a manager to be compensated on the rival firm's profits lessens competition and raises profits for both firms. Notice that the optimal contracts we derived,

$$
\begin{aligned}
& \alpha^{*}=\frac{2 b-a}{a} y, \quad \beta^{*}=y, \quad y \in \Re^{+}, \\
& \gamma^{*}=\frac{2 b-a}{a} z, \quad \delta^{*}=z, \quad z \in \Re^{+}
\end{aligned}
$$

are functions of $a$ and $b$. The relative weight put on own firm's profits in the optimal contract is an increasing function of $b$, or the weight on own price, and a decreasing function of $a$, or the weight on the rival firm's price. The ratio $b / a$ measures the degree of substitutability between the two firm's products. A higher value of $b / a$ indicates lower substitutability, i.e., an 
industry that is closer to a monopoly. A lower value of $b / a$ indicates greater substitutability, i.e., an industry that is closer to perfect competition.

The optimal contracts are only identified up to their ratio, $\alpha^{*} / \beta^{*}$, and not to their levels. This is a result of the continuum of equilibria. We call this ratio the compensation ratio. As the product market approaches a monopoly, that is

$$
\lim _{a \rightarrow 0} \frac{\alpha^{*}}{\beta^{*}}=\infty
$$

the optimal contract puts all of the weight on own-firm performance and none on rival-firm performance. As the product market approaches the perfectly competitive outcome,

$$
\lim _{a \rightarrow b} \frac{\alpha^{*}}{\beta^{*}}=1
$$

the weights on both own firm and rival firm become equalized in the optimal contract. In other words, as the products become more substitutable, more weight is put on the rival firm's profits to offset the increased competitive pressure.

The next step in the analysis is to consider the situation in which the principal allows the agent to choose her contract. For example, the principal pays the agent a fixed amount of money and allows her to allocate the funds (or some fraction thereof) between the stock of her own firm and her rival firm. In other words we are considering the agent's portfolio problem and explicitly accounting for strategic effects on portfolio choice. Mathematically, the agents now choose $\alpha, \beta, \delta$ and $\gamma$. The problem for firm 1's owner is:

$$
\begin{aligned}
& \max _{k} E\left[\pi_{1}\right]-w_{1} \\
& \text { s.t. } \quad w_{1}=k_{1}+\alpha \pi_{1}+\beta \pi_{2} \geq w_{1}^{\prime} \quad \text { and } \\
& \alpha^{\prime \prime}, \beta^{\prime \prime} \in \arg \max _{\alpha, \beta} w_{1} \\
& p_{1}^{\prime \prime} \in \arg \max _{p_{1}} w_{1}\left(\alpha^{\prime \prime}, \beta^{\prime \prime}, \gamma^{\prime \prime}, \delta^{\prime \prime}\right) .
\end{aligned}
$$


A symmetric problem holds for firm 2. $k$ will be chosen so that the IR constraint is met with equality. Therefore, we only need consider the agent's problem. The information structure here is important-the manager of firm 1 chooses her contract at the same time that the manager of firm 2 chooses her contract, the contracts are revealed, and then the firms compete (prices are chosen). Price competition yields the same prices as functions of contracts as we derived for Proposition 2.

$$
\begin{aligned}
& p_{1}^{\prime \prime}=\frac{-\gamma(A+\varepsilon)(\alpha a+2 b \alpha+\beta a)-\gamma b c(2 b \alpha+\alpha a-\beta a)+a^{2} c \delta(\alpha+\beta)}{-4 \gamma b^{2} \alpha+\alpha a^{2} \gamma+\alpha a^{2} \delta+\beta a^{2} \gamma+\beta a^{2} \delta} \\
& p_{2}^{\prime \prime}=\frac{-\alpha(A+\varepsilon)(a \delta+2 \gamma b+a \gamma)-\alpha b c(2 \gamma b-a \delta+a \gamma)+\beta a^{2} c(\delta+\gamma)}{-4 \gamma b^{2} \alpha+\alpha a^{2} \gamma+\alpha a^{2} \delta+\beta a^{2} \gamma+\beta a^{2} \delta}
\end{aligned}
$$

The manager of firm 1 chooses $\alpha$ and $\beta$ to maximize

$$
\alpha \pi_{1}+\beta \pi_{2}
$$

given the prices above and symmetrically for the manager of firm 2 . The symmetric equilibrium contracts are $\alpha^{\prime \prime}=r, \beta^{\prime \prime}=r, \gamma^{\prime \prime}=t, \delta^{\prime \prime}=t, \quad r, t \in \Re^{+}$. If we choose $\beta^{\prime \prime}=\beta^{*}$ (the contract from Proposition 2), i.e., $r=y$, then

$$
\alpha^{\prime \prime}=r<\frac{2 b-a}{a} y=\alpha^{*} .
$$

Allowing the agent to choose the contract further softens price competition. Given these contracts, Proposition 3 shows that prices and profits are higher when the manager picks her contract (or allocates her portfolio) than when the owner chooses the contract for the manager.

Proposition 3 If $E\left[p_{i}\right]>c$, then $E\left[p_{i}^{\prime \prime}\right]>E\left[p_{i}^{*}\right]$ and $E\left[\pi_{i}^{\prime \prime}\right]>E\left[\pi_{i}^{*}\right]$ for $i \in[1,2]$.

Competition is further softened because now the managers fully internalize their competitive externality. Shareholders cannot commit directly to maximizing industry profits 
because this is not credible-they can only commit to maximizing their own wealth. Letting managers choose their contracts indirectly commits firms to maximizing industry profits. Both managers choose contracts and then prices to maximize industry profitability. Because prices are strategic complements, higher prices increase joint profits, which then increase the manager's payoff.

In summary, we might expect to see compensation contracts based on own and rivalfirm profits when firms engage in differentiated Bertrand competition. Relative to standard differentiated Bertrand competition, such compensation contracts soften competition. However, firms do even better by allowing managers to allocate their wealth across the equity of their own firms and their rivals. As long as managers hold some of the equity in their own firm, they will also choose to hold equity in their rival and further attenuate Bertrand competition. Thus, it is not a requirement to observe explicit provisions regarding own and rival-firm profits in managerial contracts. The manager can be relied on to make optimal portfolio allocations.

\section{Cournot Competition}

Now we consider the same model as before but where the market is characterized by Cournot competition instead of Bertrand competition. The demand structure is:

$$
D\left(q_{1}, q_{2}\right)=A-b\left(q_{1}+q_{2}\right)+\varepsilon
$$

The standard Cournot solution obtains if the manager is strictly compensated on own-firm profits. It is given by:

$$
\max _{q_{i}} \quad q_{i}\left(A-b\left(q_{i}+q_{j}\right)+\varepsilon-c\right) .
$$


The firms' reaction functions are:

$$
\begin{aligned}
q_{i} & =\frac{1}{2} \frac{A-b q_{j}+\varepsilon-c}{b} \\
q_{j} & =\frac{1}{2} \frac{A-b q_{i}+\varepsilon-c}{b} .
\end{aligned}
$$

The firms' profit maximizing quantities are:

$$
\begin{aligned}
& q_{i}=\frac{1}{3 b}(A+\varepsilon-c) \\
& q_{j}=\frac{1}{3 b}(A+\varepsilon-c) .
\end{aligned}
$$

Expected profits are:

$$
\begin{aligned}
E\left[\pi_{i}\right] & =E\left[q_{i}\left(A-b\left(q_{i}+q_{j}\right)+\varepsilon-c\right)\right]=E\left[\frac{1}{9 b}(A+\varepsilon-c)^{2}\right] \\
& =\frac{1}{9 b}\left[(A-c)^{2}+\sigma^{2}\right] .
\end{aligned}
$$

Next we consider contracts contingent upon rival-firm profits as well as own-firm profits. First we look at the case in which only the manager of firm 1 is compensated on the rival firm's stock price in addition to her own share performance. We consider linear contracts of the following form:

$$
w_{1}=k_{1}+\alpha \pi_{1}+\beta \pi_{2}
$$

We also assume that contracts are bounded:

$$
\alpha, \beta \in[-M, M], \quad M<\infty .
$$

We now proceed as we did before in the Bertrand case. The first period program for the owner of firm 1 is:

$$
\max _{\alpha, \boldsymbol{\beta}} E\left[\pi_{1}\right]-w_{1}
$$

$$
\begin{array}{ll}
\text { s.t. } & w_{1} \geq w_{1}^{\prime} \text { and } \\
& q_{1}^{\prime} \in \arg \max _{q_{1}} w_{1} .
\end{array}
$$


The second period action choice of firm 1's manager is given by:

$$
\max _{q_{1}} \alpha q_{1}\left(A-b\left(q_{1}+q_{2}\right)+\varepsilon-c\right)+\beta q_{2}\left(A-b\left(q_{1}+q_{2}\right)+\varepsilon-c\right) .
$$

The reaction function for the manager of firm 1 is:

$$
q_{1}=\frac{1}{2} \frac{\alpha A-\alpha b q_{2}+\alpha \varepsilon-\alpha c-\beta q_{2} b}{\alpha b}
$$

For firm 2, we have the standard Cournot reaction function:

$$
q_{2}=\frac{1}{2} \frac{A-b q_{1}+\varepsilon-c}{b}
$$

Jointly solving both yields:

$$
\begin{aligned}
q_{1}^{\prime} & =(\alpha-\beta) \frac{A-c+\varepsilon}{b(3 \alpha-\beta)} \\
q_{2}^{\prime} & =\alpha \frac{A+\varepsilon-c}{b(3 \alpha-\beta)}
\end{aligned}
$$

Substituting these quantity choices back into firm 1's owner's first period problem and holding the manager to her reservation wage gives the following program:

$$
\max _{\alpha, \beta} E\left[q_{1}^{\prime}\left(A-b\left(q_{1}^{\prime}+q_{2}^{\prime}\right)-c+\varepsilon\right)\right]-w_{1}^{\prime}
$$

The solution to this program is given in the following proposition:

Proposition 4 There is a continuum of optimal contracts in which $\alpha^{\prime}=y, \beta^{\prime}=-y, y \in$ $[-M, 0) \cup(0, M]$. For all $y_{k}, y_{l} \in[-M, 0) \cup(0, M], E\left[q_{1 k}^{\prime}\right]=E\left[q_{1 l}^{\prime}\right], E\left[\pi_{1 k}^{\prime}\right]=E\left[\pi_{1 l}^{\prime}\right], E\left[q_{2 k}^{\prime}\right]=$ $E\left[q_{2 l}^{\prime}\right]$ and $E\left[\pi_{2 k}^{\prime}\right]=E\left[\pi_{2 l}^{\prime}\right]$. Therefore, we have unique quantities and payoffs $E\left[q_{1}^{\prime}\right], E\left[\pi_{1}^{\prime}\right]$, $E\left[q_{2}^{\prime}\right]$ and $E\left[\pi_{2}^{\prime}\right]$. Relative to the Cournot payoffs and quantities we have $E\left[q_{1}^{\prime}\right]>E\left[q_{1}\right]$, $E\left[\pi_{1}^{\prime}\right]>E\left[\pi_{1}\right], E\left[q_{2}^{\prime}\right]<E\left[q_{2}\right]$ and $E\left[\pi_{2}^{\prime}\right]<E\left[\pi_{2}\right]$.

This leads to firm 1 becoming a Stackelberg leader and firm 2 becoming a Stackelberg follower. Profits are higher for firm 1 when its manager is compensated on both firms' profits than when she is compensated solely on own-firm profits. Note that the optimal contracts 
can be decomposed into two types: those in which the manager of firm 1 is given a long position in her own firm and a short position in the rival and those in which the manager is given a short position in her own firm and a long position in the rival. While both are theoretically possible, legal constraints prevent a manager from shorting her own firm. Section 16(c) of the Securities Exchange Act of 1934 prohibits insiders from maintaining short positions in equity securities. ${ }^{7}$ Hansen and Lott (1995) demonstrate that no such constraints exist on taking a short position in a rival firm. We thus refer to the contract in which the manager of a firm is given a long position in her own firm and a short position in her rival as the equilibrium contract.

Next we consider if firm 2 is better off by also adopting such a contract. The contract specification is again linear:

$$
\begin{aligned}
& w_{1}=k_{1}+\alpha \pi_{1}+\beta \pi_{2} \\
& w_{2}=k_{2}+\gamma \pi_{2}+\delta \pi_{1}
\end{aligned}
$$

We assume that:

$$
\alpha, \beta, \gamma, \delta \in[-M, M]
$$

The firm's first period optimization is:

$$
\begin{aligned}
& \max _{\boldsymbol{\alpha}, \beta} E\left[\pi_{1}\right]-w_{1} \\
& \text { s.t. } \quad w_{1} \geq w_{1}^{\prime} \text { and } \\
& q_{1}^{*} \in \arg \max _{q_{1}} w_{1} .
\end{aligned}
$$

\footnotetext{
7 According to SEC Document No. S7-26-88, "A reading of the legislative history indicates that Congress did not want insiders, with access to inside information, speculating in their company's stock by acquiring short positions. Further, Congress did not want insiders to take short positions in conflict with their fiduciary duties, because insiders could use short positions to manipulate a stock price or to profit by a fall in the price of their company's stock."
} 
A symmetric program holds for firm 2. Firm 1's manager's second period action choice is given by:

$$
\max _{q_{1}} \alpha q_{1}\left(A-b\left(q_{1}+q_{2}\right)+\varepsilon-c\right)+\beta q_{2}\left(A-b\left(q_{1}+q_{2}\right)+\varepsilon-c\right)
$$

The reaction functions are:

$$
\begin{aligned}
q_{1} & =\frac{1}{2} \frac{\alpha A-\alpha b q_{2}+\alpha \varepsilon-\alpha c-\beta q_{2} b}{\alpha b} \\
q_{2} & =\frac{1}{2} \frac{\gamma A-\gamma c+\gamma \varepsilon-\delta b q_{1}-\gamma b q_{1}}{\gamma b}
\end{aligned}
$$

and optimal quantity levels are:

$$
\begin{aligned}
& q_{1}^{*}=\gamma(\beta-\alpha) \frac{A+\varepsilon-c}{b(-3 \alpha \gamma+\delta \alpha+\delta \beta+\gamma \beta)} \\
& q_{2}^{*}=\alpha(\delta-\gamma) \frac{A+\varepsilon-c}{b(-3 \alpha \gamma+\delta \alpha+\delta \beta+\gamma \beta)}
\end{aligned}
$$

Substituting these quantity choices back into the owner's first period problem and holding the manager to her reservation wage yields the following program:

$$
\max _{\alpha, \beta} E\left[q_{1}^{*}\left(A-b\left(q_{1}^{*}+q_{2}^{*}\right)+\varepsilon-c\right)\right]-w_{1}^{\prime} .
$$

A similar program holds for firm 2. Jointly solving both gives the Nash equilibrium optimal contracts for each firm's manager.

Proposition 5 There are two continua of pure strategy asymmetric Nash equilibria. In the first continuum, $\alpha^{1 *}=r, \beta^{1 *}=-r, \gamma^{1 *}=t, \delta^{1 *}=0$, and $r, t \in[-M, 0) \cup(0, M]$. For all $r_{k}, r_{l}, t \in[-M, 0) \cup(0, M], E\left[q_{1 k}^{1 *}\right]=E\left[q_{1 l}^{1 *}\right], E\left[\pi_{1 k}^{1 *}\right]=E\left[\pi_{1 l}^{1 *}\right], E\left[q_{2 k}^{1 *}\right]=E\left[q_{2 l}^{1 *}\right]$ and $E\left[\pi_{2 k}^{1 *}\right]=E\left[\pi_{2 l}^{1 *}\right]$. In the second continuum, $\alpha^{2 *}=u, \beta^{2 *}=0, \gamma^{2 *}=v, \delta^{2 *}=-v$, and $u, v \in[-M, 0) \cup(0, M]$. For all $v_{k}, v_{l}, u \in[-M, 0) \cup(0, M], E\left[q_{1 k}^{2 *}\right]=E\left[q_{1 l}^{2 *}\right], E\left[\pi_{1 k}^{2 *}\right]=E\left[\pi_{1 l}^{2 *}\right]$, $E\left[q_{2 k}^{2 *}\right]=E\left[q_{2 l}^{2 *}\right]$ and $E\left[\pi_{2 k}^{2 *}\right]=E\left[\pi_{2 l}^{2 *}\right]$. Therefore, we have unique quantities and payoffs $E\left[q_{1}^{e *}\right]$, $E\left[\pi_{1}^{e *}\right], E\left[q_{2}^{e *}\right]$ and $E\left[\pi_{2}^{e *}\right], e \in\{1,2\}$ associated with each continuum of equilibria. In all of the pure strategy Nash equilibria, one firm is a Stackelberg leader and the other is a Stackelberg follower. Joint quantities are higher and joint profits lower than in the standard Cournot model. 
As in the previous proposition, within each continuum we can decompose contracts into two types: those in which the manager is given a long position in her own firm and a short position in the rival and those in which the manager is given a short position in her own firm and a long position in the rival. Again, we will refer to this first type of contract as the equilibrium contract. The optimal contracts exhibit short-selling of the rival by one of the firms, who becomes the Stackelberg leader; that is, either $\beta^{*}$ or $\delta^{*}$ is negative. The Stackelberg follower has a long position in her own firm and no position in the rival (this is again the result of legal prohibitions against short selling of one's own firm).

It is worth noting the differences between our results and those of Fershtman and Judd (1987) and Sklivas (1987). Fershtman and Judd and Sklivas consider contracts in which the manager is compensated on a linear combination of own-firm profits and sales, and not on rival-firm profits. They show that quantities are higher and profits are lower than in the standard Cournot model. However, their models generate a unique equilibrium that does not have Stackelberg behavior. Our model has continua of asymmetric pure strategy equilibria in which the firms do exhibit Stackelberg behavior. Asymmetry is a natural feature of our model and characterizes a richer set of possible outcomes for the Cournot case.

In our model, shorting one's rival resembles relative performance evaluation. The manager does get compensated on the difference between her firm's performance and that of the rival firm. However, what looks like relative performance evaluation is not the result of the owner's need to provide the agent with incentives to supply effort while filtering out the common shock $\varepsilon$. Instead, what appears to be relative performance evaluation arises because the owner wants to toughen competition-it is a strategic choice rather than a response to moral hazard.

Next we ask the question of whether the owner would prefer to let the manager choose 
the contract, as we did in the Bertrand case. Again, this means the agents pick $\alpha, \beta, \delta$ and $\gamma$. The problem for firm 1's owner is:

$$
\begin{aligned}
& \max _{k} E\left[\pi_{1}\right]-w_{1} \\
& \text { s.t. } \quad w_{1}= k_{1}+\alpha \pi_{1}+\beta \pi_{2} \geq w_{1}^{\prime} \quad \text { and } \\
& \alpha^{\prime \prime}, \beta^{\prime \prime} \in \arg \max _{\alpha, \beta} w_{1} \\
& q_{1}^{\prime \prime} \in \arg \max _{q_{1}} w_{1}\left(\alpha^{\prime \prime}, \beta^{\prime \prime}, \gamma^{\prime \prime}, \delta^{\prime \prime}\right) .
\end{aligned}
$$

A symmetric problem holds for firm $2 . k$ will be chosen so that the IR constraint is met with equality. Therefore, we only need consider the manager's problem. The manager of firm 1 chooses her contract at the same time that the manager of firm 2 chooses her contract, the contracts are revealed, and then the firms compete (quantities are chosen). Quantity competition yields the same quantities as functions of contracts as we derived in equations 43.

$$
\begin{aligned}
& q_{1}^{\prime \prime}=\gamma(\beta-\alpha) \frac{A+\varepsilon-c}{b(-3 \alpha \gamma+\delta \alpha+\delta \beta+\gamma \beta)} \\
& q_{2}^{\prime \prime}=\alpha(\delta-\gamma) \frac{A+\varepsilon-c}{b(-3 \alpha \gamma+\delta \alpha+\delta \beta+\gamma \beta)}
\end{aligned}
$$

The manager of firm 1 chooses $\alpha$ and $\beta$ to maximize

$$
w_{1}=k_{1}+\alpha \pi_{1}+\beta \pi_{2}
$$

given the quantities above and a symmetric equation holds for the manager of firm 2 .

Proposition 6 Consider equilibria in pure strategies. The equilibria are:

$$
\alpha_{1}^{\prime \prime}=M, \beta_{1}^{\prime \prime}=M, \gamma_{1}^{\prime \prime}=M, \delta_{1}^{\prime \prime}=-M \text { and } \alpha_{2}^{\prime \prime}=M, \beta_{2}^{\prime \prime}=-M, \gamma_{2}^{\prime \prime}=M, \delta_{2}^{\prime \prime}=M .
$$

In the first equilibrium, firm 1 does not produce and firm 2 produces at the monopoly level. In equilibrium 2, firm 2 does not produce and firm 1 produces at the monopoly level. The expected payoff to both managers is $E\left[w_{i}^{\prime \prime}\right]=k_{i}+\frac{1}{4}(A+\varepsilon-c)^{2} \frac{M}{b}, i \in\{1,2\}$. 
These contracts lead one firm to be the monopolist and the other to stay out, but the manager of the firm that stays out gets compensated anyway. ${ }^{8}$ Allowing the managers to choose their contracts makes them less competitive-one firm becomes the monopolist and both managers take long positions in that firm. Clearly the owner of the firm that does not produce is made worse off in this situation-such an owner would prefer not to let her manager choose her own contract. On the other hand, each owner would like to induce her manager to produce at the monopoly level. One way to achieve this is to give a manager a sufficiently large stake in her own firm so that she cannot take an equally large long position in her rival. In this case, the best the manager can do is to short her rival, thus committing the manager to produce aggressively and to become either a monopolist (as in Proposition 6) or a Stackelberg leader (as in Proposition 5).

Next we consider what happens when one firm lets the manager choose her contract and the other firm uses no contract. The quantity functions are:

$$
\begin{aligned}
q_{1} & =(\alpha-\beta) \frac{A-c+\varepsilon}{b(3 \alpha-\beta)} \\
q_{2} & =\alpha \frac{A+\varepsilon-c}{b(3 \alpha-\beta)}
\end{aligned}
$$

The manager of firm 1 maximizes $w_{1}=k_{1}+\alpha \pi_{1}+\beta \pi_{2}$. The optimal contract turns out to be $\alpha=\beta=z, z \in(0, M]$. We conclude that if one firm wants to let its manager choose her contract, the other firm would not want to let the manager choose her contract. The firm in which the manager does not choose earns monopoly profits, and the manager who chooses does not produce.

Next we consider what happens when one manager chooses her own contract and the 8 One thing to notice about the equilibria in this case is that there are only two pure strategy equilibria, rather than two continua of equilibria which we identify generically with the same payoffs as in Proposition 5 . 
other firm dictates a contract. The quantity functions are:

$$
\begin{aligned}
& q_{1}=\gamma(\beta-\alpha) \frac{A+\varepsilon-c}{b(-3 \alpha \gamma+\delta \alpha+\delta \beta+\gamma \beta)} \\
& q_{2}=\alpha(\delta-\gamma) \frac{A+\varepsilon-c}{b(-3 \alpha \gamma+\delta \alpha+\delta \beta+\gamma \beta)}
\end{aligned}
$$

Firm 1 chooses the contract for the manager and firm 2 lets the manager choose. The optimal contract in this case is: $\delta=\gamma=M, \alpha=x, \beta=-x, x \in(0, M]$. This leads to another continuum of equilibria. Firm 1 can choose any contract where $\alpha=x, \beta=-x$ and get a monopoly position. Firm 2, by letting the manager choose, does not produce.

These cases demonstrate that there remains a strategic role for relative performance evaluation. We expect to see both firms choosing contracts for their managers. This is the situation analyzed in Proposition 5. One manager's contract will consist of aggressively short-selling the rival, i.e., there will be a contract that resembles relative performance evaluation for that manager. The other firm will select a standard compensation contract consisting of a long position in the manager's own firm.

\section{Risk Aversion}

Thus far we have assumed that the manager is risk neutral. In this section, we show that the analysis is unchanged if the manager is risk averse. This property is the consequence of our assumption that there is no disutility to the agent's action choices. To see this, recall that throughout the paper, the principals have solved programs of the following form: 


$$
\begin{array}{cc}
\max _{\alpha, \beta, k_{1}} E\left[\pi_{1}\right]-w_{1} \\
\text { s.t. } \quad w_{1}=k_{1}+\alpha \pi_{1}\left(x_{1}, x_{2}\right)+\beta \pi_{2}\left(x_{1}, x_{2}\right) \geq w_{1}^{\prime} \quad \text { and } \\
x_{1}^{*} \in \arg \max _{x_{1}} w_{1}
\end{array}
$$

In order to show that risk aversion does not matter, we need only show that the optimal action choice $x_{i}$ does not change when the manager is risk averse. This is because the principal is risk neutral in either case, and so $\alpha$ and $\beta$ will be chosen optimally given $x_{i}$ and $k_{1}$ is chosen so $w_{1}=w_{1}^{\prime}$. The optimal $x_{1}^{*}$ in the problem above is given by the solution to:

$$
\alpha \frac{\partial \pi_{1}}{\partial x_{1}}+\beta \frac{\partial \pi_{2}}{\partial x_{1}}=0
$$

A symmetric equation holds for firm 2. The principal's problem when the manager is strictly risk averse is:

$$
\max _{\alpha, \beta, k_{1}} E\left[\pi_{1}\right]-w_{1}
$$

$$
\begin{aligned}
\text { s.t. } & w_{1}=u(y) \geq w_{1}^{\prime} \text { and } \\
x_{1}^{\prime} & \in \arg \max _{x_{1}} \quad w_{1} \text { where } \\
u^{\prime} & >0, \quad u^{\prime \prime}<0 \text { and } \\
y & =k_{1}+\alpha \pi_{1}\left(x_{1}, x_{2}\right)+\beta \pi_{2}\left(x_{1}, x_{2}\right)
\end{aligned}
$$

The optimal $x_{1}^{\prime}$ in this problem is given by:

$$
\frac{\partial u}{\partial y}\left(\alpha \frac{\partial \pi_{1}}{\partial x_{1}}+\beta \frac{\partial \pi_{2}}{\partial x_{1}}\right)=0 .
$$

By assumption, $\frac{\partial u}{\partial y}>0$, so the optimal $x_{1}^{\prime}$ solves

$$
\alpha \frac{\partial \pi_{1}}{\partial x_{1}}+\beta \frac{\partial \pi_{2}}{\partial x_{1}}=0
$$


The same argument holds when the manager chooses $\alpha$ and $\beta$, i.e., the manager chooses the contract or her portfolio.

A simple contract that implements $x_{1}^{*}$ when the agent is risk averse is the following. We interpret $\alpha$ and $\beta$ as the fractions of shareholdings in firm 1 and 2 respectively for the manager of firm 1. Let $\tau$ be a constant that scales the number of shares held in each firm by the manager of firm 1 . Then the owner of firm 1 solves the following program:

$$
\begin{aligned}
& \max _{\alpha, \beta, k_{1}, \tau} E\left[\pi_{1}\right]-w_{1} \\
\text { s.t. } \quad w_{1} & =u(y) \geq w_{1}^{\prime} \quad \text { and } \\
x_{1}^{\prime} & \in \arg \max _{x_{1}} \quad w_{1} \text { where } \\
u^{\prime} & >0, \quad u^{\prime \prime}<0 \quad \text { and } \\
y & =k_{1}+\tau\left(\alpha \pi_{1}\left(x_{1}, x_{2}\right)+\beta \pi_{2}\left(x_{1}, x_{2}\right)\right)
\end{aligned}
$$

The solution is to choose $\alpha^{*}=\arg \max _{\alpha} E\left[\pi_{1}\right]-w_{1}^{\prime}$ as above, $k_{1}=u^{-1}\left(w_{1}^{\prime}\right)$, and to let $\tau \rightarrow 0$. As $\tau$ is chosen arbitrarily small, the agent is directly paid her reservation utility, bears vanishing risk, and chooses the optimal $x_{1}^{*}$. This is the least-cost way to implement the optimal action.

\section{Data}

The models of sections 2 and 3 yield testable implications regarding the relationship between product substitutability and the sensitivity of executive compensation to firm performance. We combine data from two separate sources to explore this relationship empirically. Our data on compensation are drawn from the Standard and Poor's Compustat ExecuComp database. Our data on the product market substitutability across different firms are drawn from the Censuses of Manufactures conducted by the Commerce department. This section describes each of these data sources in turn. 


\subsection{Executive Compensation Data}

The ExecuComp dataset compiled by Standard and Poor's includes data on total compensation for the top five executives (ranked annually by salary and bonus) at each of the firms in the S\&P 500, S\&P Midcap 400, and S\&P SmallCap $600 .^{9}$ In addition to measures of shortterm compensation such as salary and bonus, ExecuComp contains data on components of long-term compensation such as long-term incentive plans, restricted stock, and stock appreciation rights. Due to enhanced federal reporting requirements for fiscal years ending after December 15, 1992, the ExecuComp data for 1993 and 1994 are virtually complete. ${ }^{10}$ Relative to the datasets used in the studies by Jensen and Murphy (1990) and Gibbons and Murphy (1990), the advantages of the ExecuComp data are that its sample encompasses the largest 1500 firms each year and is not restricted to just chief executive officers. The main disadvantage is that its panel dimension for payments to executives is limited to only two years at present.

Table 1 presents descriptive statistics on the components of executive compensation for all executives in the ExecuComp sample for 1994 for whom complete data on total compensation is available. The top panel of the table pertains to the 1,490 executives who are identified as the chief executive officer of the firm. The bottom panel describes the other 6,146 executives in the sample. Our measure of total compensation can be divided into short-term compensation and long-term compensation. Short-term compensation consists of salary, bonus, and other annual payments (e.g., gross-ups for tax liabilities, perquisites, preferential

\footnotetext{
9 ExeculComp is the publicly available version of the data that have traditionally been used to tabulate the annual Business Week executive compensation scoreboards. See Byrne (1996) for the most recent scoreboard.

${ }^{10}$ There are several data items that did not have to be disclosed (e.g. other annual compensation, all other compensation) for fiscal years ending before December 15, 1992. Prior to that, disclosure was at the company's discretion. Hence, although we do have some data extending back to 1991, we focus only on the years for which we know that the set of firms reporting all the components of compensation is representative.
} 
discounts on stock purchases). Annual short-term compensation averages $\$ 973,000$ for the CEOs and $\$ 454,000$ for the Non-CEOs. Long-term compensation includes the value of restricted stock granted, stock options granted, payouts from long-term incentive plans, and all other compensation (e.g., contributions to benefit plans, severance payments). The sample averages of long-term compensation are $\$ 1,045,000$ for CEOs and $\$ 381,000$ for Non-CEOs. In the aggregate, long-term compensation accounts for 51.8 percent of CEO compensation and 45.6 percent of Non-CEO compensation. At the individual level, the average share of compensation that is long-term is 35.0 percent for CEOs and 32.1 percent for Non-CEOs, reflecting the skewness in the distribution of long-term compensation. Stock options granted are by far the most important component of long-term compensation, accounting for 72.9 percent for CEOs and 68.8 percent for Non-CEOs. ${ }^{11}$

\subsection{Product Market Data}

Our model links the compensation contract to properties of the demand curve for a firm's products. Specifically, in the differentiated Bertrand model from Section 2 with linear demand curves, the compensation contract is a function of the ratio $b / a$, where the numerator (denominator) is the slope of the demand curve with respect to the firm's (rival's) price. A firm in an industry in which there is little product differentiation will have a low ratio. Our theory predicts that the compensation of executives in such an industry will be insensitive to changes in own performance relative to rival firm performance. Compensation becomes more sensitive to own-firm performance relative to rival-firm performance as product differentiation (and the ratio $b / a$ ) increases.

Since we do not have estimates of the parameters of demand functions at the level of the

11The value of stock options granted is estimated by a proprietary modified Black-Scholes formula. See Standard and Poor's (1995) for a discussion. 
firm or even the industry, we proxy for the degree of substitutability that a firm's product faces with the firm's industry concentration ratio. We conjecture that a firm in a more concentrated industry will have fewer close substitutes for its products. This assumption is consistent with a framework such as that of Salop (1979), in which firms in each industry have located optimally in the product space to maximize the distance between competitors. In such a model, industries with more firms will have greater product substitutability and lower concentration ratios.

Our source of data on concentration ratios by industry is the 1992 Census of Manufactures, conducted by the Bureau of the Census as part of the quinquennial Economic Censuses. ${ }^{12}$ Within the manufacturing sector are the twenty 2-digit standard industrial classification (SIC) codes from 20 to 39, and within these 2-digit SICs are 458 separate 4digit SICs (ranging from 2001 to 3999). For each SIC, the Census contains five measures of industry concentration: the 4-, 8-, 20-, and 50-firm ratios and the Herfindahl index. Denoting a firm's share of the total value of shipments in the industry by $\xi_{i}$ and ordering the firms from the largest share to smallest, an industry's Herfindahl index is:

$$
H=\sum_{i=1}^{50} \xi_{i}^{2}
$$

The restriction of the Herfindahl to the largest 50 firms is a convention of the Census of Manufactures. ${ }^{13}$

Table 2 presents the average concentration ratios for each of the 2-digit SICs within

12The data and documentation of the concentration ratios for 1992 are found in Bureau of the Census (1996). More complete documentation of the concentration ratio series through 1987 is found in Bureau of the Census (1993). The Economic Censuses for other sectors of the economy do not include concentration ratios and so are excluded from our empirical analysis.

13In the few SICs in which the Herfindahl index is missing, we impute the value from the other concentration ratios by assuming that the shares of the firms within each group (i.e. 1-4, 5-8, 9-20, 21-50) are equal. This procedure will always underestimate the Herfindahl index. 
the manufacturing sector. Each cell in the table weights the concentration ratio of the constituent 4-digit SICs in proportion to their value of shipments. There is wide variation in average concentration across these broad industry groups. In our empirical work, we use the Herfindahl index as our measure of industry concentration, although our qualitative results are invariant to the particular measure of concentration that we use. We believe that the Herfindahl best captures the impact of both the number of firms and their relative market shares on the degree of product substitutability in an industry.

It is worth noting that although we use the concentration ratio as a proxy for the substitutability of products between firms in a market, the correspondence between SIC codes and product markets is not perfect. Even at the 4-digit level, some industries may include several products that are not themselves close substitutes for each other. This aggregation tends to understate the true concentration ratio for a firm's product, possibly by different amounts in different industry classifications. This consideration must be balanced against another data limitation; namely, that many firms have products in several 4-digit industries, but the firm's top executives are typically responsible for all of them, and the firm's financial statements reflect its overall performance. Conducting the analysis with more disaggregated industry classifications would exacerbate this problem. ${ }^{14}$

\footnotetext{
14In our empirical work, we use the Compustat "Principal Products" SIC code for the firm's largest business segment. For some firms in which this is given only at the 2- or 3- digit level, we impute the concentration data for the 2-digit SIC average.
} 


\section{Empirical Results}

Our model specifies executive compensation as a linear combination of own and rival-firm profits:

$$
w_{1}=k_{1}+\alpha \pi_{1}+\beta \pi_{2}
$$

Note that $\alpha$ and $\beta$ also represent the own and rival-firm pay-performance sensitivities in this linear compensation contract. The main prediction from the differentiated Bertrand model is that the relative weight of own profits relative to rival firm profits-the compensation ratio $(\alpha / \beta)$-should be a decreasing function of the degree of substitutability between the two firms' products. In other words, as products become more substitutable (markets become more competitive), an executive's pay will depend less on her own firm's performance and more on the performance of rival firms. In contrast, the main prediction of the Cournot model is that executive compensation has a constant own-firm pay-performance sensitivity regardless of the degree of competition in the product market. In this framework, $\alpha$ is positive and $\beta$ is negative or zero. To the extent that rival firms' performance matters, better rival firm performance decreases executive compensation.

As discussed above, we make two simplifying assumptions to test our theory empirically. The first is that the firm's rivals are the set of firms who also have their principal business in the same 4-digit SIC code (Below, we will also consider more aggregated industrial classifications at the 3- and 2-digit levels). The second is that the degree of substitutability in a firm's product market can be proxied by the concentration of the firm's industry. In order to estimate pay-performance sensitivities, we specify both parameters of the compensation 
contract as linear functions of the percentile of the firm's industry in the distribution of concentration ratios:

$$
\begin{aligned}
& \frac{\partial w_{1}}{\partial \pi_{1}}=\alpha=\eta_{1}+\eta_{3} F(H) \\
& \frac{\partial w_{1}}{\partial \pi_{2}}=\beta=\eta_{2}+\eta_{4} F(H)
\end{aligned}
$$

where $F(H)$ is the empirical cumulative distribution function (cdf) of the Herfindahl index across 4-digit SICs. $F(H)$ will equal zero (one) at the minimum (maximum) observed industry concentrations in our sample. ${ }^{15}$ We use the cdf of $H$ as a convenient normalization that allows for easy interpretation of the parameters, $\eta_{k}$, in a regression specification. Note that when the firm's rivals are alternatively defined as all firms within the same 3- or 2-digit SICs, we continue to use the Herfindahl for the 4-digit SIC to characterize the degree of product substitutability the firm faces.

Given the equations in 57 , the Cournot model makes the strong prediction that in a cross-section of industries: $\eta_{1}>0, \eta_{2}<0$, and $\eta_{3}=\eta_{4}=0$. Alternatively, the prediction for the Bertrand model will be empirically confirmed if the compensation ratio is an increasing function of the Herfindahl index:

$$
\frac{\partial\left(\frac{\alpha}{\beta}\right)}{\partial H}=\frac{\left(\eta_{2} \eta_{3}-\eta_{1} \eta_{4}\right) f(H)}{\left(\eta_{2}+\eta_{4} F(H)\right)^{2}}>0
$$

where $f(H)$ is the probability density function associated with $F(H)$. Since $f(H)$ is a positive number independent of the parameters, $\eta_{k}$, it can be divided out of both sides of the inequality, leaving:

\footnotetext{
15In our sample, the Herfindahl for the least concentrated industry is 15 , i.e., $F(15)=0$. Additionally, the Herfindahl is 489 at the median and 2999 for the most concentrated industry, i.e., $F(489)=0.50$ and $F(2999)$ $=1$.
} 


$$
R(\eta)=\frac{\eta_{2} \eta_{3}-\eta_{1} \eta_{4}}{\left(\eta_{2}+\eta_{4} F(H)\right)^{2}}>0 .
$$

Equation 59 is a single nonlinear restriction on the parameters of a linear regression which we fully specify below in equation $65 .{ }^{16}$ The test statistic is therefore distributed asymptotically as:

$$
W=R(\boldsymbol{\eta})^{\prime}\left(G(\boldsymbol{\eta}) \hat{V}(\boldsymbol{\eta}) G(\boldsymbol{\eta})^{\prime}\right)^{-1} R(\boldsymbol{\eta})^{\sim} \chi^{2}(1)
$$

where

$$
G(\boldsymbol{\eta})=\frac{\partial R(\boldsymbol{\eta})}{\partial \boldsymbol{\eta}^{\prime}}
$$

and $\widehat{V}(\eta)$ is the estimated variance-covariance matrix of the parameters. Note that each term in the test-statistic depends on the value of $F(H)$. In our empirical work, we test the null hypothesis for values of $F(H)$ corresponding to $0.25,0.50$, and 0.75 .

In our one-period model from sections 2 and 3 , we referred to $\pi_{j}$ as the "profits to firm j." In practice, the appropriate variable to use is the total dollar returns to shareholdersincluding capital gains and dividends but net of inflation-on their holdings at the beginning of the period. This is the concept underlying the measures of performance used by Jensen and Murphy (1990). Own performance for firm ' $\mathrm{j}$ ' is defined as:

$$
\pi_{j t}^{o}=\rho_{j t} W_{j, t-1}
$$

where $\rho_{j t}$ is the total inflation-adjusted return to shareholders and $W_{j, t-1}$ is the beginning of period market value of firm 'j.' In our dataset consisting of large firms in 1993 and 1994, ${ }^{16} \mathrm{R}(\boldsymbol{\eta})$ is also equal to $\frac{\partial\left(\frac{9}{\rho}\right)}{\partial F(H)}$. 
the mean and median values for $W_{j, t-1}$ are $\$ 3.3$ billion and $\$ 874$ million (in constant 1994 dollars), respectively. We define the total inflation-adjusted return to shareholders of rival firms as:

$$
\rho_{-j, t}=\frac{\sum_{k \neq j} \rho_{k t} W_{k, t-1}}{\sum_{k \neq j} W_{k, t-1}}
$$

where the summation is taken over all firms excluding firm ' $\mathrm{j}$ ' in the same SIC code. In our dataset, the 25 th, 50 th, and 75 th percentiles of $\rho_{j t}$ and $\rho_{-j, t}$ are $\{-12.67 \%, 5.40 \%, 26.76 \%\}$ and $\{-2.46 \%, 10.50 \%, 27.80 \%\}$, respectively. Our measure of rival firm performance is:

$$
\pi_{j t}^{r}=\rho_{-j, t} W_{j, t-1}
$$

Rival firm performance is therefore the hypothetical dollar returns to shareholders of firm ' $\mathrm{j}$ ' if it experienced the value-weighted average return of other firms in its industry. Studies of relative performance evaluation typically include $\pi_{j t}^{o}-\pi_{j t}^{r}$ as an explanatory variable in a regression for compensation. We extend that framework first by including the two components separately and, second, by allowing both pay-performance sensitivities to vary across industries in proportion to their concentration ratio. Accordingly, we estimate the following equation:

$$
\begin{aligned}
w_{i j t}= & \eta_{1} \pi_{j t}^{o}+\eta_{2} \pi_{j t}^{r}+\eta_{3} F\left(H_{j}\right) \pi_{j t}^{o}+\eta_{4} F\left(H_{j}\right) \pi_{j t}^{r}+ \\
& \eta_{5} F\left(H_{j}\right)+\eta_{6} C E O_{i t}+\sum_{k=20}^{39} \sum_{t=93}^{94} \lambda_{j k t}+\varepsilon_{i j t}
\end{aligned}
$$

In this equation, the executive 'i' works at firm ' $j$ ' in year ' $t$.' The dependent variable is compensation (in constant 1994 dollars), and the first four independent variables are own and rival firm performance, alone and interacted with the cdf of the Herfindahl index. The 
regressions also include the cdf of the Herfindahl itself and an indicator variable that is equal to one if the executive is a CEO and zero otherwise. The remaining terms, denoted by $\lambda_{j k t}$, are indicator variables for whether firm ' $\mathrm{j}$ ' is in the 2-digit SIC ' $\mathrm{k}$ ' in year ' $\mathrm{t}$. .'17 The inclusion of these indicator variables ensures that it is not the variation in the average pay-performance sensitivities between 2-digit industry groups but the variation in the pay-performance sensitivity within those groups that identifies the estimated coefficient. Including the industry effects also controls for any other factor such as a macroeconomic shock that varies across broad industry groups but not within the narrow industries that comprise them. Note that we cannot estimate the model with a more disaggregated fixed effect (e.g., at the level of the firm or the executive) because our measure of the Herfindahl index does not vary across executives in a given firm or over the two years of data in the sample.

Table 3a presents the estimates of equation 65 with total compensation as the dependent variable. In all specifications, executive compensation is denominated in thousands and frm performance is denominated in millions of constant 1994 dollars. The first column pertains to a regression in which the firm's rivals are all other firms in the sample with the same 4digit SIC code. The first coefficient shows that an executive's total compensation increases by 0.11 cents for every thousand dollars of incremental shareholder wealth per year in an industry that has the minimum industry concentration (i.e., the one for which $F(H)=0$ and is therefore the most competitive). The third coefficient shows that this pay-performance sensitivity increases by another 7.92 cents per thousand as industry concentration increases from the least to the most concentrated. Thus, the pay-performance sensitivity is 8.03 cents per thousand at the maximum industry concentration (i.e., the one for which $F(H)=1)$ ).

The second and fourth coefficients show that the rival pay-performance sensitivity is 32.66 170ne of the $\lambda_{j k t}$ terms is omitted from the regression to avoid linear dependence among the explanatory variables. 
cents per thousand in the least concentrated (i.e., most competitive) industries and declines to $32.66-34.10=-1.44$ cents per thousand in the most concentrated (i.e., least competitive) industries. The rival pay-performance sensitivity changes from positive to negative at the 96th percentile of the Herfindahl index distribution. As shown in the table, at the median industry concentration, the own pay-performance sensitivity is $0.11+0.50 * 7.92=4.07$ cents per thousand and the rival pay-performance sensitivity is $32.66-0.50 * 34.10=15.61$ cents per thousand. In their estimates of the pay-performance sensitivity, Jensen and Murphy (1990) found that for total compensation, the pay-performance sensitivity was 3.29 cents per thousand. ${ }^{18}$ The result that the rival pay-performance sensitivity is positive rather than negative over almost the entire distribution of industries is inconsistent with models such as Gibbons and Murphy (1990) which emphasize relative performance evaluation. This result also contradicts the predictions of the Cournot model that we derived in section 3 .

Although our model abstracts from all other factors that might cause one executive to be paid more than another, in actual data we have to allow for these factors. In addition to the full set of 2-digit industry and year interactions, we also include the percentile of the Herfindahl index itself and a dummy variable that takes on a value of one if the executive is a $\mathrm{CEO}$ and zero otherwise. Including the cdf of the Herfindahl allows for the level of compensation to be different in more concentrated industries, independent of own and rival performance. The fifth row in the table shows that total compensation increases by approximately $\$ 38,000$ for every decile increase in the distribution of the Herfindahl index. Including the indicator variable is motivated by the differences in the level (more so than in the composition) of executive compensation revealed in Table 1. The last coefficient shows 18 Jensen and Murphy (1990) had a longitudinal sample of CEOs from large corporations. Their measure
of total pay used in this comparison did not include the value of stock options granted. Additionally, they
used the change in compensation as their dependent variable, whereas we control for broad industry effects. 
that CEOs receive approximately $\$ 1$ million more in total compensation than do non-CEOs, a number that is similar to the unconditional difference shown in Table 1.

The bottom panel of the table presents the tests of the nonlinear restriction on the parameters $\left\{\eta_{1}, \eta_{2}, \eta_{3}, \eta_{4}\right\}$ specified as $R(\eta)>0$ that is implied by our differentiated Bertrand model. In the first entry, where the value of $F(H)$ is set equal to 0.25 , the value of the restriction is 0.4504 and the test statistic is 15.4154 . Since the test statistic is asymptotically distributed chi-square with one degree of freedom, the null hypothesis that the compensation ratio is not increasing with $H$ is strongly rejected with a p-value of 0.0001 . The null hypothesis is similarly rejected for $F(H)=0.50$ and rejected at the 4 percent significance level for $F(H)=0.75$. The higher p-values at higher percentiles indicate that we can have less confidence that the compensation ratio is still increasing with respect to industry concentration once industries have become highly concentrated. The strong results for the hypothesis tests can be traced to the pattern of signs on the estimates for $\left\{\eta_{1}, \eta_{2}, \eta_{3}, \eta_{4}\right\}$. A sufficient but not necessary condition for $R(\eta)>0$ to obtain is that $\eta_{4}$ be negative and $\eta_{1}, \eta_{2}$, and $\eta_{3}$ be positive. This condition will result in $\frac{\partial \alpha}{\partial H}>0$ and $\frac{\partial \beta}{\partial H}<0$, which in turn will guarantee that the compensation ratio is increasing in $H$.

The second and third columns of Table $3 \mathrm{a}$ extend the definition of the rival firms to those in the same 3-digit and 2-digit SICs, respectively. The second column shows that when the 3-digit SIC is used, the parameter estimates, median pay-performance sensitivities, and hypothesis tests are similar in magnitude and significance to those in the 4-digit SIC specification. The third column shows that when the 2-digit SIC is used, $\eta_{3}$ is negative (though with only marginal significance). Given the magnitudes of the other parameters, this is enough to make the restriction on the own and rival-firm pay-performance sensitivities insignificantly negative rather than significantly positive. It is not surprising that the model 
fails under such a broad definition of the firm's rivals. It is unlikely that strategic interactions between firms are as important at the 2-digit level as they are at the narrower 4-digit level. ${ }^{19}$

Table $3 \mathrm{~b}$ presents the estimates of the same three regressions using short-term compensation as the dependent variable. The results are very similar to those in Table $3 \mathrm{a}$. When the rivals are defined at the 4-digit or 3-digit SIC level, the null hypothesis that the compensation ratio does not increase with industry concentration is strongly rejected. Unlike the regressions for total compensation, there is no industry concentration level at which the rival-firm pay-performance sensitivity is negative. At the median industry concentration, the own and rival-firm pay-performance sensitivities are 3.21 and 4.11 cents per thousand, respectively, for the 4-digit SIC rivals and 3.19 and 5.23 cents per thousand for 3-digit SIC rivals. These results are somewhat higher than Jensen and Murphy's (1990) range of estimates from 1.35 to 2.19 cents per thousand for salary plus bonus. When the definition of rivals is extended to the 2-digit SIC level, the restriction value is again negative though not statistically significant.

The skewness of the distribution of many of the components of executive compensation documented in Table 1 raises the possibility that the results in Table 3 are being unduly influenced by outliers. Tables $4 \mathrm{a}$ and $4 \mathrm{~b}$ estimate the same specifications from Tables $3 \mathrm{a}$ and $3 \mathrm{~b}$ using median regression. Because median regression minimizes the sum of absolute deviations rather than the sum of squared deviations, it is less sensitive to outliers than is ordinary least squares. Using this method, the estimates for each of the six specifications provide stronger support for the predictions of our differentiated Bertrand model: all of the test statistics are positive and significant below the 0.1 percent significance level, in19It is noteworthy that Gibbons and Murphy (1990) found larger negative effects in broader industry groups in their estimates of a relative performance evaluation model. 
cluding those for the 2-digit SIC definition of rivals, which were previously negative and insignificant. $^{20}$ The parameter estimates for $\left\{\eta_{1}, \eta_{2}, \eta_{3}, \eta_{4}\right\}$ are typically more positive than in Table 3, resulting in higher values of the own pay-performance sensitivity. At the median industry concentration, own and rival pay-performance sensitivities are 8.44 and 12.20 cents per thousand for the 4-digit SICs for total compensation. They are 5.61 and 5.20 cents per thousand for short-term compensation. The median regressions estimate smaller effects for the CEO and the industry concentration variables. Thus, the main results from the OLS regressions are supported and strengthened by the median regressions.

The optimal contracts based on the parameter estimates for the 4-digit and 3-digit SIC specifications from Table 4 are graphed in Figures 2 and 3, respectively. In each graph, the horizontal axis represents $\mathrm{F}(\mathrm{H})$ and the vertical axis represents the regression estimate of the compensation ratio:

$$
\frac{\widehat{\alpha}}{\widehat{\beta}}=\frac{\widehat{\eta_{1}}+\widehat{\eta_{3}} F(H)}{\widehat{\eta_{2}}+\widehat{\eta_{4}} F(H)}
$$

for both total and short-term compensation. Each of the four curves is upward sloping, as predicted by the differentiated Bertrand model. In both figures, the total compensation ratio varies more with industry concentration than does the short-term compensation ratio. ${ }^{21}$ The greater sensitivity of the total compensation ratio to industry concentration suggests that shareholders rely more on long-term compensation to accommodate strategic interactions and that the incentive effects of long-term compensation are greater than those of shortterm compensation.

\footnotetext{
20The variance-covariance matrix of the parameters and goodness of fit statistic are estimated using the method of Koenker and Bassett (1982) and Rogers (1993), as described in StataCorp (1995).

21To enhance the graph's readability, the curves in Figure 2 extend only through the 95th percentile of $\mathrm{F}(\mathrm{H})$. Beyond that percentile, the compensation ratio $(\alpha / \beta)$ for total compensation increases rapidly to a maximum value of 11.37 .
} 
In Tables 3 and 4, we have constrained the own and rival-firm pay-performance sensitivities to be equal for CEOs and non-CEOs, allowing only their average level of compensation to differ. In Tables 5 and 6 , we relax that assumption and estimate the same set of regressions restricting the sample to only CEOs. The results are qualitatively the same as in the full sample of executives, with larger magnitudes on all of the coefficients. The pay-performance sensitivities will be higher in the sample of CEOs because they bear more responsibility for decisions within the firm that affect own profits and within the industry that affect rival profits. Based on the OLS estimation for total compensation, reported in Table 5a, the own and rival pay-performance sensitivities at the median industry concentration are 3.10 and 40.34 cents per thousand for 4 -digit SICs and 10.50 and 38.44 cents per thousand for 3-digit SICs. Based on the median regressions (Table 6a), the median own and rival payperformance sensitivities are 7.25 and 41.17 cents per thousand for 4-digit SICs and 7.45 and 41.03 cents per thousand for 3-digit SICs. Thus, the main difference between the estimates for CEOs and those for the full sample is a higher rival pay-performance sensitivity, not a higher own pay-performance sensitivity. The tests of the restriction implied by the differentiated Bertrand model are similar to those in the full sample but offer weaker statistical evidence. For the 4-digit and 3-digit SIC specifications, the restriction value is always positive, but it is statistically significant in the OLS regressions only at median industry concentration or below. The test still rejects the null hypothesis at a significance level below ten percent in the corresponding median regressions.

Throughout our theoretical and empirical work, we have limited our measure of total compensation to the annual flow of resources that the shareholders could have kept for themselves had they not used it to compensate the executive. In practice, an executive also receives incentives from the effects of her actions on the value of her holdings of stock in 
her own firm and in her rival firms. If an executive owns stock in her firm, then the total increase in her wealth due to the performance of her firm will include not only the extra pay she receives as part of the pay-performance sensitivity built into her compensation but the appreciation on her personal stock holdings. ${ }^{22}$ Recognizing this, the shareholders of her firm will incorporate a lower own-firm pay-performance sensitivity into her contract. If the manager's holdings of her rival firms' stock were also known, then her compensation contract would include a lower rival-firm pay-performance sensitivity as well.

The consequences of an executive's personal wealth holdings are straightforward in our framework. The optimal compensation contract becomes a function of both the degree of substitutability in the product market and the executive's holdings of her own firm and her rivals. Conditional on a particular allocation of the executive's personal wealth, however, the relationship between product substitutability and the compensation ratio takes the same form as in the model of section 2 .

In order for our econometric specifications to remain valid, we would have to control for the executive's holdings of her own and rival firms. Since it is impossible to obtain data on the executive's holdings of her rival firms, we cannot modify our regressions in this way. ${ }^{23}$ In order to test for the robustness of our findings to the incentives provided by inside ownership, we stratify our sample into two groups of executives: those who had less than the median wealth in their own firm at the beginning of the sample year and those who had more than the median. We then run the regressions from Table 3a separately for each group 22 Of the overall $\$ 3.25$ per thousand that Jensen and Murphy (1990) estimated for the pay-performance sensitivity, fully $\$ 2.50$ was related to changes in wealth due to stockholdings. Another $\$ 0.30$ was related to changes in wealth due to dismissal for poor performance.

${ }^{23}$ Additionally, ExecuComp does not contain data on the value of stock options held at the beginning of 1993 for many of the executives in our sample. Thus, accounting for the change in the value of the executive's claims on her own firm would eliminate half of our sample. 
of executives. The median wealth in the executive's own firm in our sample is approximately $\$ 400,000$.

The results of these regressions for the 4-digit SIC and 3-digit SIC specifications are presented in Table 7. The bottom panel shows that the null hypothesis, that the restriction implied by the differentiated Bertrand model is not satisfied, is rejected at significance levels below five percent at the 25 th percentile of industry concentration. The null hypothesis is rejected at significance levels of approximately ten percent or below at the median concentration. At the 75th percentile, the restriction value is always positive, but the p-values are approximately 0.30 for the low ownership sample and 0.20 for the high ownership sample. Thus, if the model had been tested only on these smaller groups, it would still be largely supported by the data. More importantly, the middle panel shows that the comparison of the compensation ratios across the two groups supports the predictions of the model. The compensation ratio is higher in the subsample of executives who have low holdings of their own firms. In the 4-digit SIC specification, the ratio is 1.5441 in the low ownership group and 0.1080 in the high ownership group. In the 3-digit SIC specification, the ratios are 1.1643 and 0.1996.

The results presented in Table 7 support the differentiated Bertrand model in two distinct ways. First, the compensation ratio is increasing in both the low ownership and high ownership subsamples. Second, the compensation ratio itself is greater in the low ownership group than in the high ownership group. In the high ownership group, executives already receive high-powered incentives from their own personal stock holdings. They have a correspondingly lower compensation ratio. We conclude that the empirical confirmation of the predictions from our differentiated Bertrand model are robust to the omission of the executive's personal wealth from the model. 
The regressions of executive compensation on firm performance in Tables 3 through 6 provide strong empirical support for the differentiated Bertrand model derived in section 2 . Under the assumption that the Herfindahl index for a firm's 4-digit SIC is an appropriate proxy for the degree of product substitutability, our results show that the sensitivity of compensation to own performance relative to rival performance decreases with the degree of product substitutability. Based on these results, we conclude that strategic interactions have important effects on the structure of executive compensation.

\section{Discussion}

In our model, compensation contracts are used to influence the nature of competition-in the case of Bertrand competition, to soften it. There are two major strands in the literature that consider the effects of competition on the nature of optimal contracts. The first literature examines the effects of product market competition on agency problems, and the second literature analyzes the importance of competition for relative performance evaluation.

The research of Hart (1983), Scharfstein (1988), and Hermalin (1992) considers whether or not market competition induces managers to run their firms more efficiently by increasing their supply of effort. Hart (1983) assumes that the manager's utility is infinitely negative below a certain income threshold. This implies that the manager is paid a fixed wage if she achieves a certain profit target. In equilibrium, when competition increases, firm profits and the manager's wage are constant and the manager's effort increases. The first empirical prediction is that the own-firm pay-performance sensitivity is positive $\left(\eta_{1}+\eta_{3} F(H)>0\right)$. This prediction is borne out by the data. Second, there is no cross-sectional correlation between industry concentration and the manager's own-firm pay-performance sensitivity $\left(\eta_{3}=0\right)$. This prediction is usually rejected in our empirical work. Third, there is no 
correlation between the manager's compensation and rival firm performance $\left(\eta_{2}+\eta_{4} F(H)=\right.$ $0)$. This prediction receives no empirical support in our data.

Scharfstein (1988) allows the manager to be risk averse (but not infinitely so) and derives the optimal contracts when a productivity parameter is hidden information. In his model, managerial effort, firm profits, and compensation as a share of profits all decrease when competition increases. Notice that this model implies that managerial effort will decrease (not increase) in response to an increase in competition, the opposite of Hart's (1983) result. Our empirical results support three cross-sectional predictions of this model: that the own-firm pay-performance sensitivity is positive $\left(\eta_{1}+\eta_{3} F(H)>0\right)$, that this sensitivity is increasing with industry concentration $\left(\eta_{3}>0\right)$, and that the level of compensation is increasing with industry concentration $\left(\eta_{5}>0\right)$. Scharfstein's model provides no predictions regarding the rival-firm pay-performance sensitivity. It is therefore silent on two of our more robust findings; namely, that the rival-firm pay-performance sensitivity is positive $\left(\eta_{2}+\eta_{4} F(H)>0\right)$ and increasing with the degree of product market competition $\left(\eta_{4}<0\right)$. Thus, Scharfstein's model cannot fully explain our empirical results. ${ }^{24}$

The relative performance evaluation literature, particularly the work of Lazear and Rosen (1981), Holmström (1982), and Gibbons and Murphy (1990), shows that a risk-averse manager's compensation should be insulated from common industry-wide shocks to profits. Relative performance evaluation filters out the common shock by placing a negative weight on rival firm's performance. This is true for evaluation of both effort and ability. For effort, relative performance evaluation allows the principal to infer the agent's effort choice-this is simply an application of Holmström's (1979) sufficient statistic result. For ability, relative 24Hermalin (1992) generalizes the results of Hart (1983) and Scharfstein (1988) by identifying several different effects which determine whether or not increasing competition increases the manager's effort. As Hermalin's results are ambiguous (by design), his model does not have clear empirical predictions. The results of Hart and Scharfstein can be viewed as polar cases of Hermalin's general setup. 
performance evaluation allows the principal to disentangle the confounding effects of noise and infer the agent's ability. Our finding of a significant and positive coefficient on rival firm's performance when explaining executive compensation is clearly inconsistent with the predictions of the relative performance evaluation literature.

\section{Conclusion}

We have derived the optimal contracts in a principal-agent model of strategic competition in which managers can be compensated on both their own profits and their rival's (or industry) profits. We demonstrate that when competition is differentiated Bertrand, the optimal contract compensates the manager positively on both own and rival-firm performance. This contract has the effect of softening competition. We show that the fraction of compensation based on rival firm performance is increasing in the degree of competition in the industry. The need to soften competition is highest in those industries that are most competitive. In this case, relative performance evaluation, the natural consequence of the principal-agent framework, would lower returns to shareholders.

When competition is Cournot, the optimal contract compensates the manager positively on own-firm performance and negatively on rival-firm performance. This contract intensifies competition and leads to one firm achieving Stackelberg leadership and the other firm becoming a Stackelberg follower. Such contracts look very much like relative performance evaluation, but the impetus for their use comes from the nature of competition, not an agency problem.

Our empirical findings are consistent with the predictions from our differentiated Bertrand model and are inconsistent with the predictions from a standard principal-agent model, a relative performance evaluation model, and our model of Cournot competition. Firms op- 
erating in product markets that are more competitive rely less on high-powered incentives to compensate their managers than do firms in less competitive industries. More generally, the magnitude of own-firm pay-performance sensitivity is explicitly linked to the magnitude of the rival-firm pay-performance sensitivity. Thus, what is important for executive compensation and incentives is the ratio of the pay-performance sensitivities, not the absolute magnitude of either. That only this compensation ratio is identified may provide an explanation for the widely observed low own-firm pay-performance sensitivity.

Our theoretical and empirical work also provides an explanation of the Jensen and Murphy (1990) finding that relative performance pay is not an important source of managerial incentives. If managerial decisions are strategic complements, then relative performance pay induces managers to compete too aggressively from the shareholders' perspective. When the shareholders' objective is to foster collusion, it may be more important to ignore relative performance to avoid aggressive behavior rather than to use it to more clearly infer the precise action taken by the manager. The notion that shareholders should exclude potentially useful information (the performance of rival firms) to avoid giving the manager incentives to distort that information shows clearly the potential conflict between strategic competition and the standard principal-agent trade-off of insurance and incentives. ${ }^{25}$ Our analysis shows that providing insurance may come at the cost of not only lower effort in the production process but detrimental levels of production itself.

Our results suggest a reinterpretation of some of the findings of Gibbons and Murphy (1990). They motivate their use of executive pay as a way to test a more general theory of relative performance evaluation based on the assumption that "because CEOs tend to 25A related point was made by Gibbons and Murphy (1992), who argued that basing compensation on potentially informative accounting measures can be counterproductive because their use distracts managers from maximizing economic profits toward maximizing the more readily observed accounting profits. 
have limited interaction with CEOs in rival firms, sabotage and collusive shirking seem unlikely" (p. 31-S). We start from a different premise; namely, that the nature of oligopolistic competition makes executives in rival firms interact in ways that are fundamental to the objectives of the firms' shareholders. As Gibbons and Murphy go on to note, "Paying workers based on relative performance instead of absolute performance distorts the worker's incentives whenever the worker can take actions that affect the average output of the reference group" (p. 34-S). In our framework, pay based on relative performance would give the executive an incentive to price too aggressively in a differentiated Bertrand model, opposing the shareholders' objectives to soften competition. The Gibbons and Murphy result that CEO performance is more likely to be evaluated relative to aggregate market movements than to industry movements is consistent with our model. Value-maximizing shareholders do not give their executives strong incentives to outperform their most immediate competition. Within narrow industries, product market considerations are likely to dominate considerations of relative performance. To the extent that shareholders provide insurance to their executives as dictated by the standard principal-agent model, they rely more heavily on benchmarks that do not interfere with strategic competition.

Finally, we believe that a model of executive compensation that incorporates product market considerations can help to answer an outstanding question in the literature on incentives. In "A Survey of Corporate Governance," Shleifer and Vishny (1996, p. 56) note that:

Given the large impact of executives' actions on values of firms, why aren't very high powered incentive contracts used more often in the United States and elsewhere in the world? Is their use limited by optimal design of incentives, by fear of self-dealing, or by distributive politics? 
The principal-agent model's emphasis on the trade-off between incentives and insurance ignores the importance of strategic competition in product markets to the value of the firm. Our model predicts that product market competition is fundamental to the way shareholders structure managerial incentives. Our empirical work confirms this idea. Thus, we offer a straightforward explanation for the infrequent use of high-powered incentives-they are typically not optimal for shareholders. 


\section{REFERENCES}

Bureau of the Census (1993). 1987 Economic Censuses CD-ROM Volume 1: Report Series, Release 1E: Parts 1 and 2 Technical Documentation. Washington: The Bureau.

Bureau of the Census (1996). "Concentration Ratios in Manufacturing," 1992 Census of Manufactures, Report MC92-S-2. Washington: The Bureau [producer and distributor].

Byrne, John A. (1996). "How High Can CEO Pay Go?" Business Week. April 22,1996, $100-122$.

Fershtman, Chaim and Kenneth Judd (1987). "Equilibrium Incentives in Oligopoly," American Economic Review. Vol. 77, No. 5, 927-940.

Finkelstein, Sydney and Hambrick, Donald C. (1996). Strategic Leadership: Top Executives and Their Effects on Organizations. St. Paul, MN: West.

Fumas, Vicente Salas (1992). "Relative Performance Evaluation of Management: The Effects on Industrial Compensation and Risk Sharing," International Journal of Industrial Organization. Vol. 10, No. 3, 473-489.

Gibbons, Robert and Kevin J. Murphy (1990). "Relative Performance Evaluation for Chief Executive Officers," Industrial and Labor Relations Review. Vol. 43 Special Issue, 30-S - 51-S.

Gibbons, Robert and Kevin J. Murphy (1992). "Optimal Incentive Contracts in the Presence of Career Concerns," Journal of Political Economy. Vol. 100, No. 3, 468-505.

Hansen, Robert and John Lott, Jr. (1995). "Profiting from Induced Changes in Competitors' Market Values: The Case of Entry and Entry Deterrence," Journal of Industrial Economics (forthcoming).

Hart, Oliver (1983). "The Market Mechanism as an Incentive Scheme," Bell Journal of Economics. Vol.14, 366-82.

Haubrich, Joseph G. (1994). "Risk Aversion, Performance Pay, and the Principal-Agent Problem," Journal of Political Economy. Vol. 102, No. 2, 258-276.

Hermalin, Benjamin E. (1992) "The Effects of Competition on Executive Behavior," Rand Journal of Economics. Vol. 23, No. 3, 350-365.

Holmström, Bengt (1979). "Moral Hazard and Observability," Bell Journal of Economics. Vol. 10, 74-91. 
Holmström, Bengt (1982). "Moral Hazard in Teams," Bell Journal of Economics. Vol. $13,324-340$.

Jensen, Michael and Kevin J. Murphy (1990). "Performance Pay and Top Management Incentives." Journal of Political Economy. Vol. 98, No. 2, 225-64.

Katz, Michael L. (1991). "Game-Playing Agents: Unobservable Contracts as Precommitments," Rand Journal of Economics. Vol. 22, No. 3, 307-328.

Koenker, R. and G. Bassett, Jr. (1982). "Robust Tests for Heteroscedasticity Based on Regression Quantiles," Econometrica 50, 43-61.

Lazear, Edward and Sherwin Rosen (1981). "Rank-Order Tournaments as Optimum Labor Contracts." Journal of Political Economy. Vol. 89, No. 5, 841-64.

Reitman, David (1993). "Stock Options and the Strategic Use of Managerial Incentives," American Economic Review. Vol. 83, No. 3, 513-524.

Rogers, W. H. (1993). "Quantile Regression Standard Errors," Stata Technical Bulletin 13, 18-19.

Salop, Steven (1979). "Monopolistic Competition with Outside Goods," Bell Journal of Economics. Vol.10, 141-56.

Scharfstein, David (1988). "Product Market Competition and Managerial Slack," Rand Journal of Economics. Vol. 19, 147-55.

Securities and Exchange Commission (1988). "Ownership Reports and Trading by Officers, Directors, and Principal Stockholders," SEC File No. S7-26-88. December 2, 1988.

Shleifer, Andrei and Robert W. Vishny (1996). "A Survey of Corporate Governance," National Bureau of Economic Research, Working Paper No. 5554, April.

Sklivas, Steven (1987). "The Strategic Choice of Managerial Incentives," Rand Journal of Economics. Vol. 18, No. 3, 452-458.

Standard and Poor's (1995). S\&P Compustat ExecuComp: The Executive Compensation Database. Englewood, CO: McGraw-Hill, November.

StataCorp. (1995). Stata Statistical Software: Release 4.0. College Station, TX: Stata Corporation.

Vickers, John (1987). "Delegation and the Theory of the Firm," Economic Journal. Supplement, 138-147. 


\section{Appendix}

\section{Proof of Proposition 1:}

$$
\begin{aligned}
& E\left[p_{1}^{\prime}\right]=\frac{1}{2} \frac{c\left(a b+2 b^{2}-a^{2}\right)+A(a+2 b)}{2 b^{2}-a^{2}} \\
& E\left[p_{1}\right]=\frac{A+b c}{2 b-a} \\
& E\left[p_{1}^{\prime}\right]>E\left[p_{1}\right] \Rightarrow\left(c\left(a b+2 b^{2}-a^{2}\right)+A(a+2 b)\right)(2 b-a)-(A+b c)\left(4 b^{2}-2 a^{2}\right)>0 \\
& \left(c\left(a b+2 b^{2}-a^{2}\right)+A(a+2 b)\right)(2 b-a)-(A+b c)\left(4 b^{2}-2 a^{2}\right)=a^{2}(A+a c-b c) . \\
& A+a c-b c>0 \Leftrightarrow E\left[p_{1}\right]>c . \\
& \frac{A+b c}{2 b-a}>c \Rightarrow A+b c>(2 b-a) c \Rightarrow A+a c-b c>0 .
\end{aligned}
$$

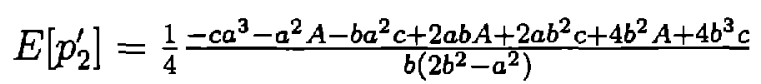

$$
\begin{aligned}
& E\left[p_{2}^{\prime}\right]>E\left[p_{2}\right] \Rightarrow\left(-c a^{3}-a^{2} A-b a^{2} c+2 a b A+2 a b^{2} c+4 b^{2} A+4 b^{3} c\right)(2 b-a)- \\
& 4 b\left(2 b^{2}-a^{2}\right)(A+b c)>0 \\
& \left(-c a^{3}-a^{2} A-b a^{2} c+2 a b A+2 a b^{2} c+4 b^{2} A+4 b^{3} c\right)(2 b-a)-4 b\left(2 b^{2}-a^{2}\right)(A+b c) \\
& =c a^{4}-c a^{3} b+a^{3} A=a^{3}(A+a c-b c)>0 . \\
& p_{1}=\frac{A+b c+\varepsilon}{2 b-a} \\
& p_{2}=\frac{A+b c+\varepsilon}{2 b-a} \\
& E\left[\pi_{1}\right]=\left(p_{1}-c\right)\left(A-b p_{1}+a p_{2}+\varepsilon\right)=E\left[\left(\frac{A+b c+\varepsilon}{2 b-a}-c\right)\left(A-b \frac{A+b c+\varepsilon}{2 b-a}+a \frac{A+b c+\varepsilon}{2 b-a}+\varepsilon\right)\right] \\
& =b \frac{A^{2}-2 A b c+2 A a c+b^{2} c^{2}-2 b c^{2} a+\sigma^{2}+a^{2} c^{2}}{(-2 b+a)^{2}} \text {. } \\
& p_{1}^{\prime}=\frac{1}{2} \frac{a^{2} c-a b c-a \varepsilon-a A-2 b^{2} c-2 b \varepsilon-2 b A}{a^{2}-2 b^{2}} \\
& p_{2}^{\prime}=\frac{1}{4} \frac{c a^{3}+a^{2} \varepsilon+a^{2} A+b a^{2} c-2 a b \varepsilon-2 a b A-2 a b^{2} c-4 b^{2} A-4 b^{2} \varepsilon-4 b^{3} c}{b\left(a^{2}-2 b^{2}\right)} \\
& E\left[\pi_{1}^{\prime}\right]=E\left[\left(p_{1}^{\prime}-c\right)\left(A-b p_{1}^{\prime}+a p_{2}^{\prime}+\varepsilon\right)\right] \\
& =E\left(\frac{1}{2} \frac{a^{2} c-a b c-a \varepsilon-a A-2 c b^{2}-2 \varepsilon b-2 A b}{a^{2}-2 b^{2}}-c\right)\left(\begin{array}{c}
A+\varepsilon-\frac{1}{2} b \frac{a^{2} c-a b c-a \varepsilon-a A-2 c b^{2}-2 \varepsilon b-2 A b}{a^{2}-2 b^{2}}+ \\
\frac{1}{4} a \frac{c a^{3}+a^{2} \varepsilon+a^{2} A+b a^{2} c-2 a b \varepsilon-2 a b A-2 a b^{2} c-4 b^{2} A-4 b^{2} \varepsilon-4 b^{3} c}{b\left(a^{2}-2 b^{2}\right)}
\end{array}\right) \\
& =-\frac{1}{8} \frac{-4 a b^{3} c^{2}+2 a^{3} b c^{2}-8 b^{3} A c+4 a b \sigma^{2}-3 a^{2} b^{2} c^{2}+a^{2} \sigma^{2}+a^{2} A^{2}+a^{4} c^{2}+2 a^{3} A c+4 b^{4} c^{2}+4 b^{2} \sigma^{2}+4 b^{2} A^{2}+6 a^{2} A b c+4 a b A^{2}}{b\left(a^{2}-2 b^{2}\right)}
\end{aligned}
$$




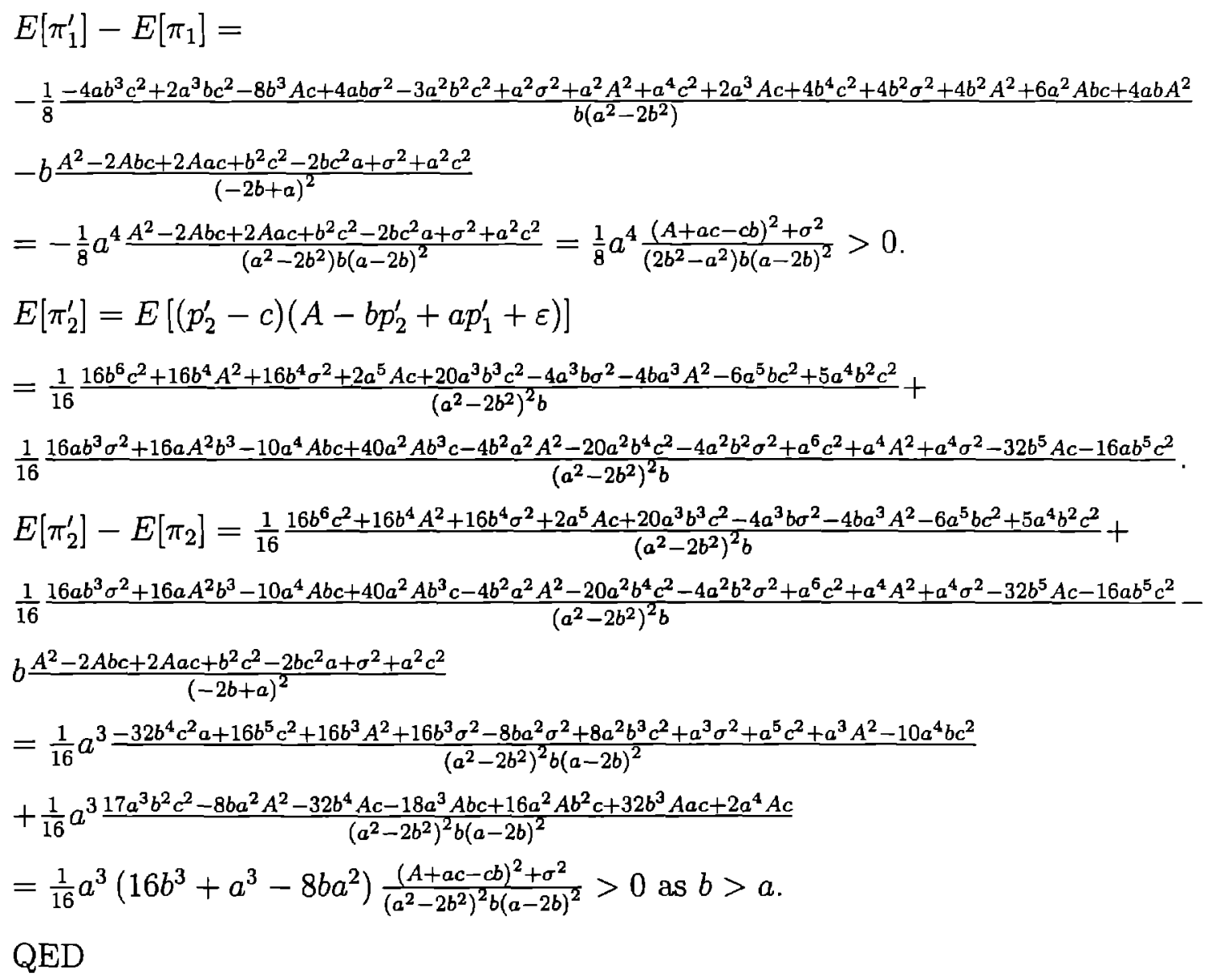

\section{Proof of Proposition 2:}

$$
\begin{aligned}
& E\left[p_{2}^{*}\right]=\frac{A(2 b-a)+c(b-a)(2 b+a)}{4 b(b-a)} \\
& E\left[p_{2}^{\prime}\right]=\frac{1}{4} \frac{-c a^{3}-a^{2} A-b a^{2} c+2 a b A+2 a b^{2} c+4 b^{2} A+4 b^{3} c}{b\left(2 b^{2}-a^{2}\right)} \\
& E\left[p_{2}^{*}\right]>E\left[p_{2}^{\prime}\right] \Rightarrow \\
& 4 b\left(2 b^{2}-a^{2}\right)(A(2 b-a)+c(b-a)(2 b+a))- \\
& 4 b(b-a)\left(-c a^{3}-a^{2} A-b a^{2} c+2 a b A+2 a b^{2} c+4 b^{2} A+4 b^{3} c\right) \\
& =-4 a^{2} c b^{3}+4 a^{2} A b^{2}+4 c a^{3} b^{2}=4 a^{2} b^{2}(A+a c-b c)>0 \\
& E\left[p_{1}^{*}\right]=\frac{A(2 b-a)+c(b-a)(2 b+a)}{4 b(b-a)} \\
& E\left[p_{1}^{\prime}\right]=\frac{1}{2} \frac{c\left(a b+2 b^{2}-a^{2}\right)+A(a+2 b)}{2 b^{2}-a^{2}}
\end{aligned}
$$




$$
\begin{aligned}
& E\left[p_{1}^{*}\right]>E\left[p_{1}^{\prime}\right] \Rightarrow \\
& (A(2 b-a)+c(b-a)(2 b+a))\left(4 b^{2}-2 a^{2}\right)-4 b(b-a)\left(c\left(a b+2 b^{2}-a^{2}\right)+A(a+2 b)\right) \\
& =2 a^{3} A-2 c a^{3} b+2 c a^{4}=2 a^{3}(A+a c-b c)>0 . \\
& p_{1}^{*}=\frac{1}{4} \frac{A(2 b-a)+c(b-a)(2 b+a)+2 b \varepsilon-a \varepsilon}{b(b-a)} \\
& p_{2}^{*}=\frac{1}{4} \frac{A(2 b-a)+c(b-a)(2 b+a)+2 b \varepsilon-a \varepsilon}{b(b-a)} \\
& E\left[\pi_{1}^{*}\right]=\left(p_{1}^{*}-c\right)\left(A-b p_{1}^{*}+a p_{2}^{*}+\varepsilon\right) \\
& =E\left[\left(\frac{1}{4} \frac{A(2 b-a)+c(b-a)(2 b+a)+2 b \varepsilon-a \varepsilon}{b(b-a)}-c\right)\left(\begin{array}{c}
A-\frac{1}{4} \frac{A(2 b-a)+c(b-a)(2 b+a)+2 b \varepsilon-a \varepsilon}{b-a}+ \\
\frac{1}{4} a \frac{A(2 b-a)+c(b-a)(2 b+a)+2 b \varepsilon-a \varepsilon}{b(b-a)}+\varepsilon
\end{array}\right)\right] \\
& =\frac{1}{16} \frac{c^{2} a^{4}-2 c^{2} a^{3} b+2 A a^{3} c+A^{2} a^{2}+\sigma^{2} a^{2}-2 a^{2} A b c-3 a^{2} b^{2} c^{2}-8 A a c b^{2}+8 b^{3} c^{2} a-4 \sigma^{2} b^{2}-4 A^{2} b^{2}-4 b^{4} c^{2}+8 A b^{3} c}{(-b+a) b^{2}} \\
& =E\left[\pi_{2}^{*}\right] \text {. } \\
& E\left[\pi_{1}^{*}\right]-E\left[\pi_{1}^{\prime}\right]= \\
& \frac{1}{16} \frac{c^{2} a^{4}-2 c^{2} a^{3} b+2 A a^{3} c+A^{2} a^{2}+\sigma^{2} a^{2}-2 a^{2} A b c-3 a^{2} b^{2} c^{2}-8 A a c b^{2}+8 b^{3} c^{2} a-4 \sigma^{2} b^{2}-4 A^{2} b^{2}-4 b^{4} c^{2}+8 A b^{3} c}{(-b+a) b^{2}} \\
& +\frac{1}{8} \frac{-4 a b^{3} c^{2}+2 a^{3} b c^{2}-8 b^{3} A c+4 a b \sigma^{2}-3 a^{2} b^{2} c^{2}+a^{2} \sigma^{2}+a^{2} A^{2}+a^{4} c^{2}+2 a^{3} A c+4 b^{4} c^{2}+4 b^{2} \sigma^{2}+4 b^{2} A^{2}+6 a^{2} A b c+4 a b A^{2}}{b\left(a^{2}-2 b^{2}\right)} \\
& =\frac{1}{16} a^{3} \frac{2 b^{3} c^{2}+2 b A^{2}-3 a b^{2} c^{2}+2 a^{2} A c-4 A b^{2} c+2 a A b c+a^{3} c^{2}+a A^{2}+2 b \sigma^{2}+a \sigma^{2}}{(-b+a) b^{2}\left(a^{2}-2 b^{2}\right)} \\
& =\frac{1}{16} a^{3}(a+2 b) \frac{(A+a c-b c)^{2}+\sigma^{2}}{(-b+a) b^{2}\left(a^{2}-2 b^{2}\right)}>0 . \\
& E\left[\pi_{2}^{*}\right]-E\left[\pi_{2}^{\prime}\right]= \\
& \frac{1}{16} \frac{c^{2} a^{4}-2 c^{2} a^{3} b+2 A a^{3} c+A^{2} a^{2}+\sigma^{2} a^{2}-2 a^{2} A b c-3 a^{2} b^{2} c^{2}-8 A a c b^{2}+8 b^{3} c^{2} a-4 \sigma^{2} b^{2}-4 A^{2} b^{2}-4 b^{4} c^{2}+8 A b^{3} c}{(-b+a) b^{2}} \\
& -\frac{1}{16} \frac{16 b^{6} c^{2}+16 b^{4} A^{2}+16 b^{4} \sigma^{2}+2 a^{5} A c+20 a^{3} b^{3} c^{2}-4 a^{3} b \sigma^{2}-4 b a^{3} A^{2}-6 a^{5} b c^{2}+5 a^{4} b^{2} c^{2}}{\left(a^{2}-2 b^{2}\right)^{2} b} \\
& -\frac{1}{16} \frac{16 a b^{3} \sigma^{2}+16 a A^{2} b^{3}-10 a^{4} A b c+40 a^{2} A b^{3} c-4 b^{2} a^{2} A^{2}-20 a^{2} b^{4} c^{2}-4 a^{2} b^{2} \sigma^{2}+a^{6} c^{2}+a^{4} A^{2}+a^{4} \sigma^{2}-32 b^{5} A c-16 a b^{5} c^{2}}{\left(a^{2}-2 b^{2}\right)^{2} b} \\
& =\frac{1}{16} a^{4}\left(-3 b^{2}+a^{2}-b a\right) \frac{(A+a c-b c)^{2}+\sigma^{2}}{\left(a^{2}-2 b^{2}\right)^{2}(-b+a) b^{2}}>0 \text {. } \\
& \alpha^{\prime}=\beta \frac{4 b^{2}+2 a b-a^{2}}{(a+2 b) a}>\frac{4 b^{2}-a^{2}}{(a+2 b) a} \beta=\frac{2 b-a}{a} \beta=\alpha^{*} \text {. } \\
& \text { QED }
\end{aligned}
$$




\section{Proof of Proposition 3}

$E\left[p_{i}^{\prime \prime}\right]=\frac{1}{2} \frac{A+c b-c a}{b-a}>\frac{A(2 b-a)+c(b-a)(2 b+a)}{4 b(b-a)}=E\left[p_{1}^{*}\right] \Rightarrow$

$(A+c b-c a) 4 b(b-a)-(2 b-2 a)(A(2 b-a)+c(b-a)(2 b+a))$

$=2 a(b-a)(c a-c b+A)>0$.

$E\left[\pi_{1}^{\prime \prime}\right]=\left(p_{1}^{\prime \prime}-c\right)\left(A-b p_{1}^{\prime \prime}+a p_{2}^{\prime \prime}+\varepsilon\right)=$

$E\left[\left(\frac{1}{2} \frac{A+c b-c a+\varepsilon}{b-a}-c\right)\left(A-b \frac{1}{2} \frac{A+c b-c a+\varepsilon}{b-a}+a \frac{1}{2} \frac{A+c b-c a+\varepsilon}{b-a}+\varepsilon\right)\right]=\frac{1}{4} \frac{(c a+A-c b)^{2}+\sigma^{2}}{b-a}$

$>\frac{1}{16}(2 b-a)(2 b+a) \frac{(c a-c b+A)^{2}+\sigma^{2}}{(b-a) b^{2}}=E\left[\pi_{1}^{*}\right] \Rightarrow$

$\left((c a+A-c b)^{2}+\sigma^{2}\right) 16(b-a) b^{2}-\left((c a-c b+A)^{2}+\sigma^{2}\right)(2 b-a)(2 b+a)(4 b-4 a)$

$=4 a^{2}(b-a)\left((c a+A-c b)^{2}+\sigma^{2}\right)>0$.

QED

\section{Proof of Proposition 4}

$q_{1}^{\prime}=(\alpha-\beta) \frac{A+\varepsilon-c}{b(3 \alpha-\beta)}$

$q_{2}^{\prime}=\alpha \frac{A+\varepsilon-c}{b(3 \alpha-\beta)}$

$E\left[\pi_{1}^{\prime}\right]=(\alpha-\beta)\left((A-c)^{2}+\sigma^{2}\right) \frac{\alpha}{b(3 \alpha-\beta)^{2}}$

$\frac{\partial E\left[\pi_{1}^{\prime}\right]}{\partial \alpha}=\left((A-c)^{2}+\sigma^{2}\right) \beta \frac{\alpha+\beta}{b(3 \alpha-\beta)^{3}}=0$

$\frac{\partial E\left[\pi_{1}^{\prime}\right]}{\partial \beta}=-\left((A-c)^{2}+\sigma^{2}\right) \alpha \frac{\alpha+\beta}{b(3 \alpha-\beta)^{3}}=0$.

Jointly solving both FOC's yields:

$\alpha^{\prime}=\alpha, \beta^{\prime}=-\alpha$.

Substituting these contracts into quantity and profit functions yields:

$E\left[q_{1}^{\prime}\right]=\frac{1}{2} \frac{A-c}{b}$

$E\left[q_{2}^{\prime}\right]=\frac{1}{4} \frac{A-c}{b}$

$E\left[\pi_{1}^{\prime}\right]=\frac{1}{8} \frac{(A-c)^{2}+\sigma^{2}}{b}$

$E\left[\pi_{2}^{\prime}\right]=\frac{1}{16} \frac{(A-c)^{2}+\sigma^{2}}{b}$. 
These quantities and profits correspond to firm 1 achieving Stackelberg leadership and firm 2 being a Stackelberg follower. Note that neither the quantity nor the profit expressions depend upon the contracts, so any feasible choice of contract values yields the same quantity choices and profit levels. Lastly note that:

$E\left[\pi_{1}^{\prime}\right]=(\alpha-\beta)\left((A-c)^{2}+\sigma^{2}\right) \frac{\alpha}{b(3 \alpha-\beta)^{2}}$ is undefined for $\alpha^{\prime}=0, \beta^{\prime}=0$. The same holds true for firm 2's profits and both quantity choices. Therefore, $\alpha \in[-M, 0) \cup(0, M]$.

QED

\section{Proof of Proposition 5}

$$
\begin{aligned}
& q_{1}^{*}=\gamma(\beta-\alpha) \frac{A+\varepsilon-c}{b(-3 \alpha \gamma+\delta \alpha+\delta \beta+\gamma \beta)} \\
& q_{2}^{*}=\alpha(\delta-\gamma) \frac{A+\varepsilon-c}{b(-3 \alpha \gamma+\delta \alpha+\delta \beta+\gamma \beta)} \\
& E\left[\pi_{1}^{*}\right]=\gamma(\alpha-\beta)\left((A-c)^{2}+\sigma^{2}\right) \frac{\alpha \gamma-\delta \beta}{b(-3 \alpha \gamma+\delta \alpha+\delta \beta+\gamma \beta)^{2}} \\
& E\left[\pi_{2}^{*}\right]=\alpha(\gamma-\delta)\left((A-c)^{2}+\sigma^{2}\right) \frac{\alpha \gamma-\delta \beta}{b(-3 \alpha \gamma+\delta \alpha+\delta \beta+\gamma \beta)^{2}} \\
& \frac{\partial E\left[\pi_{1}^{*}\right]}{\partial \alpha}=\gamma \beta(A+\varepsilon-c)^{2}(\delta-\gamma) \frac{-3 \delta \beta+\delta \alpha+\gamma \beta+\alpha \gamma}{(-3 \alpha \gamma+\delta \alpha+\delta \beta+\gamma \beta)^{3} b}=0 \\
& \frac{\partial E\left[\pi_{\pi}^{*}\right]}{\partial \beta}=-\gamma \alpha(A+\varepsilon-c)^{2}(\delta-\gamma) \frac{-3 \delta \beta+\delta \alpha+\gamma \beta+\alpha \gamma}{(-3 \alpha \gamma+\delta \alpha+\delta \beta+\gamma \beta)^{3} b}=0 \\
& \frac{\partial E\left[\pi_{2}^{*}\right]}{\partial \gamma}=-\alpha \delta(A+\varepsilon-c)^{2}(\alpha-\beta) \frac{-3 \delta \beta+\delta \alpha+\gamma \beta+\alpha \gamma}{(-3 \alpha \gamma+\delta \alpha+\delta \beta+\gamma \beta)^{3} b}=0 \\
& \frac{\partial E\left[\pi_{2}^{*}\right]}{\partial \delta}=\alpha \gamma(A+\varepsilon-c)^{2}(\alpha-\beta) \frac{-3 \delta \beta+\delta \alpha+\gamma \beta+\alpha \gamma}{(-3 \alpha \gamma+\delta \alpha+\delta \beta+\gamma \beta)^{3} b}=0 .
\end{aligned}
$$

Jointly solving all four FOCs for the maxima yields two solutions:

$\alpha^{1 *}=\alpha, \beta^{1 *}=-\alpha, \gamma^{1 *}=\gamma, \delta^{1 *}=0$,and $\alpha^{2 *}=\alpha, \beta^{2 *}=0, \gamma^{2 *}=\gamma, \delta^{2 *}=-\gamma$.

Substituting these contracts into quantity and profit functions yields:

$$
\begin{aligned}
& E\left[q_{1}^{1 *}\right]=\frac{1}{2} \frac{A-c}{b} \\
& E\left[q_{2}^{1 *}\right]=\frac{1}{4} \frac{A-c}{b} \\
& E\left[\pi_{1}^{1 *}\right]=\frac{1}{8} \frac{(A-c)^{2}+\sigma^{2}}{b} \\
& E\left[\pi_{2}^{1 *}\right]=\frac{1}{16} \frac{(A-c)^{2}+\sigma^{2}}{b} \\
& E\left[q_{1}^{2 *}\right]=\frac{1}{4} \frac{A-c}{b}
\end{aligned}
$$




$$
\begin{aligned}
& E\left[q_{2}^{2 *}\right]=\frac{1}{2} \frac{A-c}{b} \\
& E\left[\pi_{1}^{2 *}\right]=\frac{1}{16} \frac{(A-c)^{2}+\sigma^{2}}{b} \\
& E\left[\pi_{2}^{2 *}\right]=\frac{1}{8} \frac{(A-c)^{2}+\sigma^{2}}{b}
\end{aligned}
$$

These quantities and profits correspond to firm 1 achieving Stackelberg leadership and firm 2 being a Stackelberg follower in the first equilibrium and firm 2 achieving Stackelberg leadership and firm 1 being a Stackelberg follower in the second equilibrium. Note that neither the quantity nor the profit expressions depend upon the contracts, so any feasible choice of contract values yields the same quantity choices and profit levels.

Next note that:

$E\left[\pi_{1}^{*}\right]=\gamma(\alpha-\beta)\left((A-c)^{2}+\sigma^{2}\right) \frac{\alpha \gamma-\delta \beta}{b(-3 \alpha \gamma+\delta \alpha+\delta \beta+\gamma \beta)^{2}}$ is undefined for $\alpha^{*}=0, \beta^{*}=0$ and $E\left[\pi_{2}^{*}\right]=\alpha(\gamma-\delta)\left((A-c)^{2}+\sigma^{2}\right) \frac{\alpha \gamma-\delta \beta}{b(-3 \alpha \gamma+\delta \alpha+\delta \beta+\gamma \beta)^{2}}$ is undefined for $\gamma^{*}=0, \delta^{*}=0$. The same holds true for quantity choices. Therefore, $\alpha, \gamma \in[-M, 0) \cup(0, M]$.

QED

\section{Proof of Proposition 6}

$$
\begin{aligned}
& E\left[\pi_{i}^{\prime \prime}\right]=\left((A-c)^{2}+\sigma^{2}\right) \\
& q_{1}^{\prime \prime}=\gamma(\beta-\alpha) \frac{A+\varepsilon-c}{b(-3 \alpha \gamma+\delta \alpha+\delta \beta+\gamma \beta)} \\
& q_{2}^{\prime \prime}=\alpha(\delta-\gamma) \frac{A+\varepsilon-c}{b(-3 \alpha \gamma+\delta \alpha+\delta \beta+\gamma \beta)} \\
& w_{1}^{\prime \prime}=k_{1}+\alpha q_{1}^{\prime \prime}\left(A-b\left(q_{1}^{\prime \prime}+q_{2}^{\prime \prime}\right)+\varepsilon-c\right)+\beta q_{2}^{\prime \prime}\left(A-b\left(q_{1}^{\prime \prime}+q_{2}^{\prime \prime}\right)+\varepsilon-c\right) \\
& =k_{1}+\alpha(A+\varepsilon-c)^{2} \frac{(\alpha \gamma-\delta \beta)^{2}}{b(3 \alpha \gamma-\delta \alpha-\delta \beta-\gamma \beta)^{2}} \\
& w_{2}^{\prime \prime}=k_{2}+\gamma q_{2}^{\prime \prime}\left(A-b\left(q_{1}^{\prime \prime}+q_{2}^{\prime \prime}\right)+\varepsilon-c\right)+\delta q_{1}^{\prime \prime}\left(A-b\left(q_{1}^{\prime \prime}+q_{2}^{\prime \prime}\right)+\varepsilon-c\right) \\
& =k_{2}+\gamma(A+\varepsilon-c)^{2} \frac{(\alpha \gamma-\delta \beta)^{2}}{b(-3 \alpha \gamma+\delta \alpha+\delta \beta+\gamma \beta)^{2}}
\end{aligned}
$$

Because there is no interior maximum, the first order conditions do not characterize an equilibrium. In order to find equilibria, we examine the extreme points for contracts.

Suppose that the manager of firm 1 chooses $\alpha=M, \beta=M$. This generates payoffs of: 


$$
\begin{aligned}
& w_{1}^{\prime \prime}=k_{1}+\frac{1}{4}(A+\varepsilon-c)^{2} \frac{M}{b} \\
& w_{2}^{\prime \prime}=k_{2}+\frac{1}{4}(A+\varepsilon-c)^{2} \frac{\gamma}{b} .
\end{aligned}
$$

The manager of firm 2's best response then is to choose $\gamma$ as large as possible, or $\gamma=M$, and $\delta$ can be arbitrary. In order to characterize an equilibrium, we must find a $\delta$ along with $\gamma=M$ that make $\alpha=M, \beta=M$ the best response for the manager of firm 1. Setting $\delta=-M$ results in a payoff to the manager of firm 1 of:

$$
w_{1}^{\prime \prime}=k_{1}+\frac{1}{16}(A+\varepsilon-c)^{2} \frac{(\alpha+\beta)^{2}}{\alpha b} .
$$

It is immediate that $\alpha>0$ in order for the manager of firm 1 to earn a positive payoff. Further, in order for firm 1's quantity choice to be nonnegative, it must be the case that $\alpha \geq \beta$ because

$$
q_{1}^{\prime \prime}=\gamma(\beta-\alpha) \frac{A+\varepsilon-c}{b(-3 \alpha \gamma+\delta \alpha+\delta \beta+\gamma \beta)}=-\frac{1}{4}(\beta-\alpha) \frac{A+\varepsilon-c}{b \alpha} .
$$

But the manager of firm 1's payoff is increasing in $\beta$, which results in $\alpha=\beta=M$, which establishes the equilibrium. In this case, the manager of firm 1 produces $q_{1}^{\prime \prime}=0$ and the manager of firm 2 produces at the monopoly level, $q_{2}^{\prime \prime}=\frac{1}{2} \frac{A+\varepsilon-c}{b}$. The manager's expected payoffs are:

$$
\begin{aligned}
& E\left[w_{1}^{\prime \prime}\right]=k_{1}+\frac{1}{4}\left((A-c)^{2}+\sigma^{2}\right) \frac{M}{b} \\
& E\left[w_{2}^{\prime \prime}\right]=k_{2}+\frac{1}{4}\left((A-c)^{2}+\sigma^{2}\right) \frac{M}{b} .
\end{aligned}
$$

As the managers share monopoly rents, this outcome cannot be improved on for the managers. As both $\alpha$ and $\gamma$ must be positive, the other extreme point to check is $\alpha=$ $M, \beta=-M$. Because the problem is symmetric, we have already analyzed this situation for the manager of firm 2, and so we have found our two pure strategy equilibria. As no internal solutions exist, these are the only pure strategy equilibria.

QED 
Figure 1

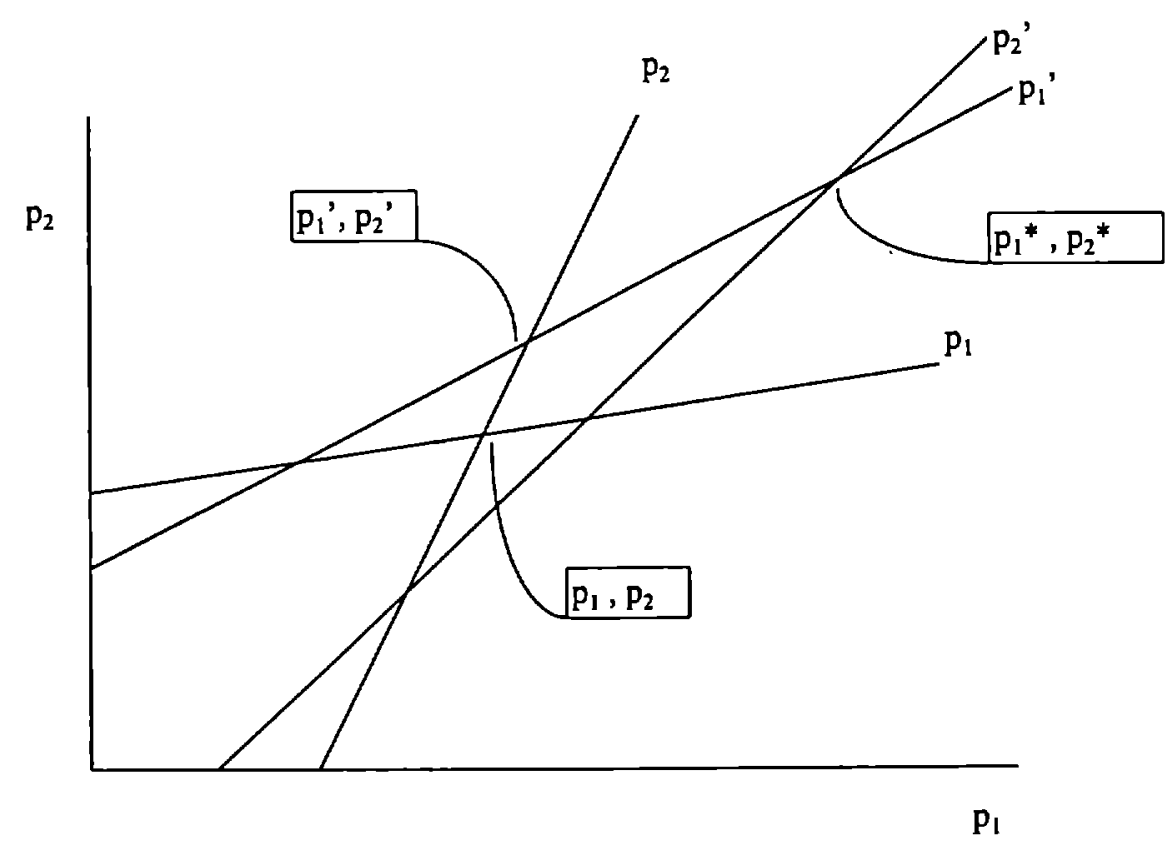

Bertrand Reaction Functions 
Figure 2

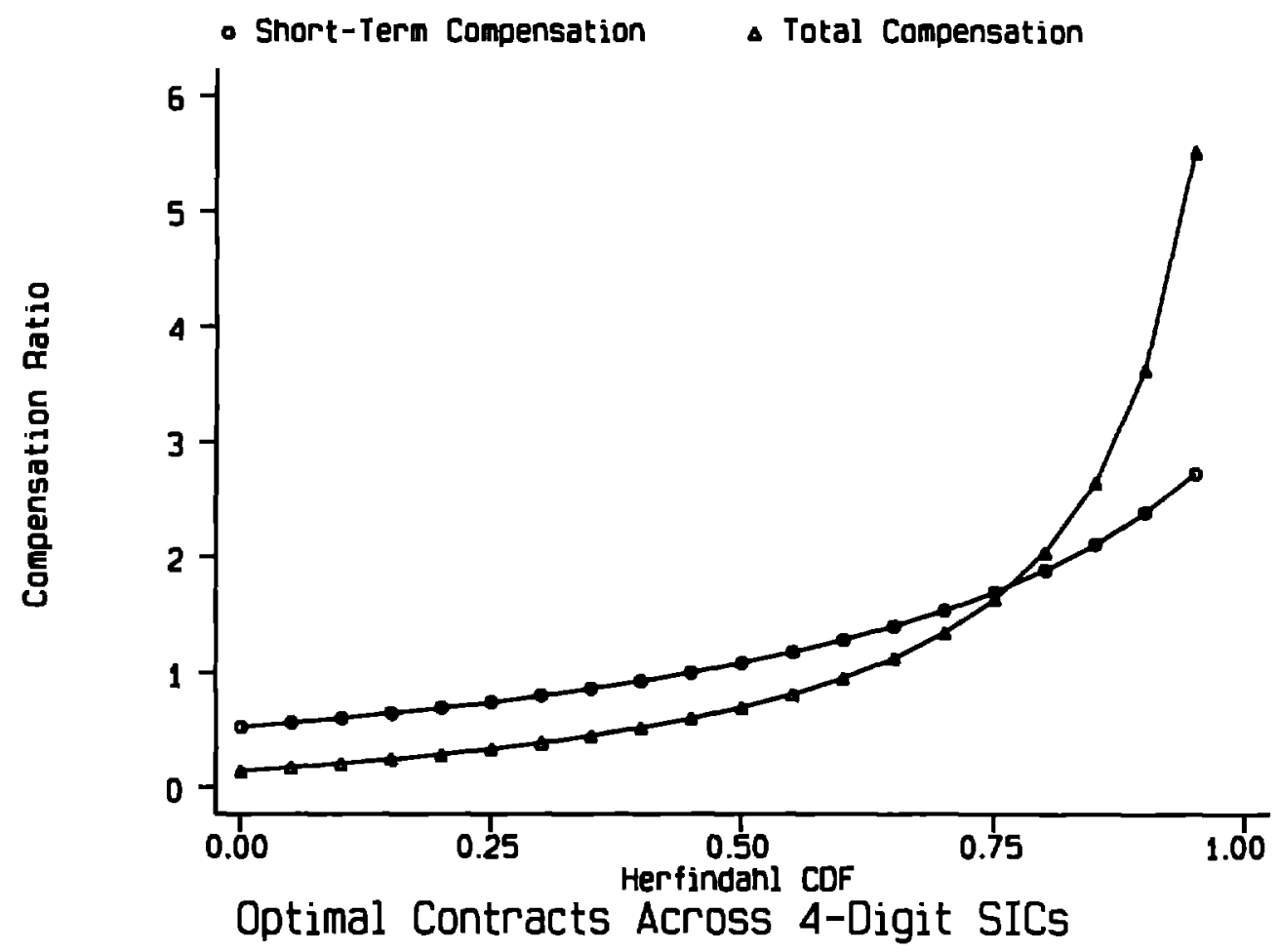

Figure 3

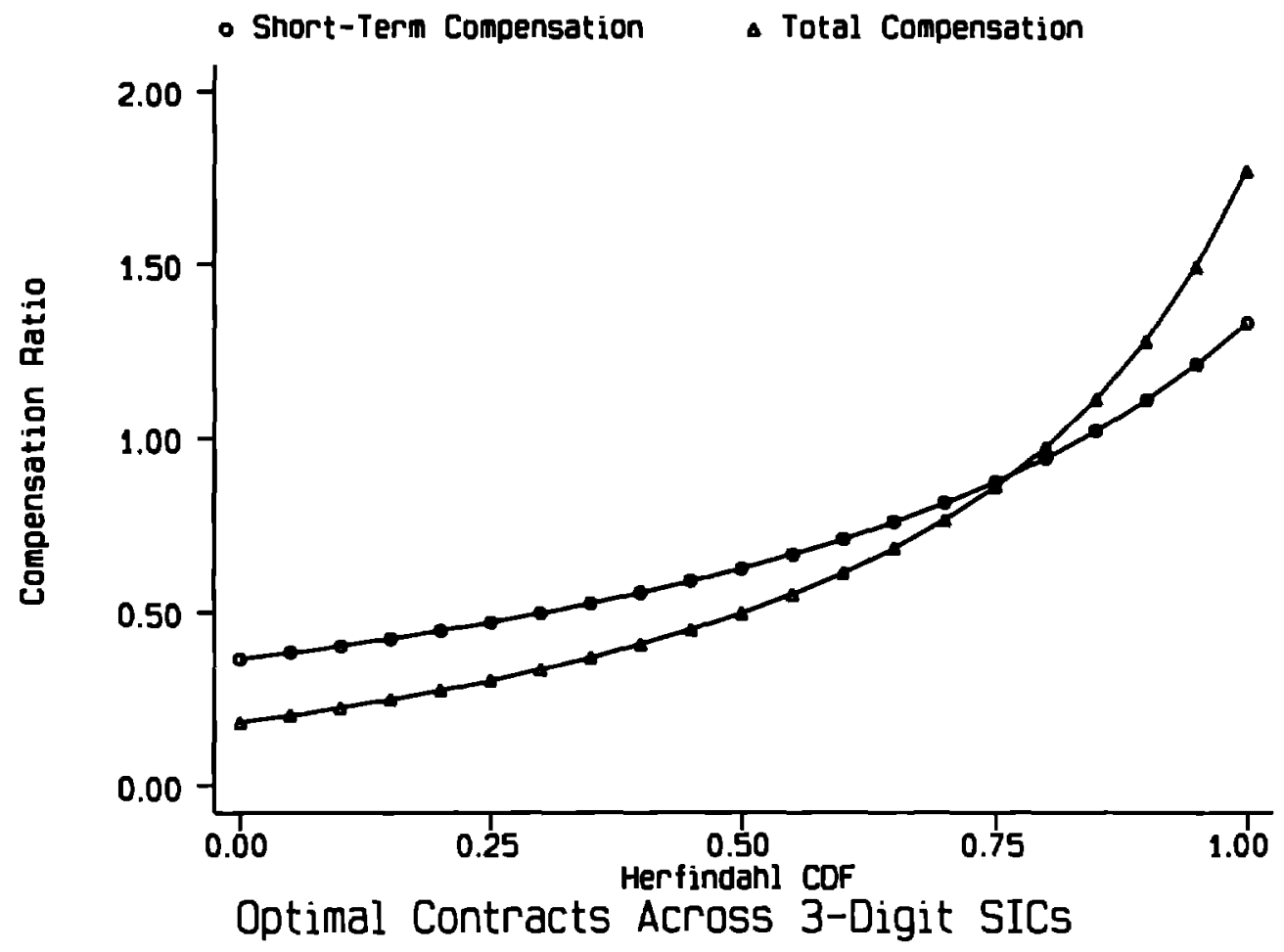




\begin{tabular}{|c|c|c|c|c|c|}
\hline \multicolumn{6}{|c|}{$\begin{array}{c}\text { Table } 1 \\
\text { Components of Executive Compensation in } 1994\end{array}$} \\
\hline $\begin{array}{l}\text { Payment Category } \\
\text { (Thousands of Dollars) }\end{array}$ & Mean & Median & $\begin{array}{c}\text { First } \\
\text { Quartile }\end{array}$ & $\begin{array}{l}\text { Third } \\
\text { Quartile }\end{array}$ & $\begin{array}{l}\text { Standard } \\
\text { Deviation }\end{array}$ \\
\hline \multicolumn{6}{|l|}{ CEOs $(\mathrm{N}=1490)$} \\
\hline Total Compensation & 2019 & 1203 & 664 & 2301 & 2637 \\
\hline Short Term Compensation & 973 & 719 & 459 & 1154 & 940 \\
\hline Salary & 515 & 458 & 323 & 650 & 278 \\
\hline Bonus & 420 & 250 & 73 & 510 & 673 \\
\hline Other Annual & 39 & 0 & 0 & 6 & 346 \\
\hline Long Term Compensation & 1045 & 417 & 63 & 1088 & 2131 \\
\hline Restricted Stock Granted & 124 & 0 & 0 & 0 & 596 \\
\hline Stock Options Granted & 762 & 225 & 0 & 785 & 1806 \\
\hline LT Incentive Plan Payouts & 78 & 0 & 0 & 0 & 379 \\
\hline All Other & 81 & 16 & 5 & 59 & 353 \\
\hline Long-Term Share of Total & 0.350 & 0.350 & 0.100 & 0.545 & 0.259 \\
\hline \multicolumn{6}{|l|}{ Non-CEOs $(\mathrm{N}=6146)$} \\
\hline Total Compensation & 836 & 533 & 311 & 966 & 1055 \\
\hline Short Term Compensation & 454 & 339 & 226 & 538 & 453 \\
\hline Salary & 266 & 229 & 167 & 325 & 144 \\
\hline Bonus & 174 & 97 & 31 & 203 & 354 \\
\hline Other Annual & 14 & 0 & 0 & 0 & 99 \\
\hline Long Term Compensation & 381 & 152 & 37 & 412 & 797 \\
\hline Restricted Stock Granted & 51 & 0 & 0 & 0 & 316 \\
\hline Stock Options Granted & 262 & 94 & 0 & 274 & 612 \\
\hline LT Incentive Plan Payouts & 32 & 0 & 0 & 0 & 147 \\
\hline All Other & 36 & 9 & 3 & 25 & 194 \\
\hline Long-Term Share of Total & 0.321 & 0.309 & 0.119 & 0.480 & 0.230 \\
\hline \multicolumn{6}{|c|}{$\begin{array}{l}\text { Notes: } \\
\text { 1) Source: Authors' tabulations of Standard and Poor's ExecuComp dataset. } \\
\text { 2) The group of CEOs is comprised of the executives at each company that held the CEO position for the } \\
\text { majority of the year. The group of Non-CEOs is comprised of the other four highest paid executives } \\
\text { ranked by salary plus bonus. }\end{array}$} \\
\hline
\end{tabular}


Table 2

Average 4-digit SIC Concentration Ratios by 2-digit SIC Code, 1992

\begin{tabular}{|l|ccccc||}
\hline Industry Code and Description & 4-firm & 8 -firm & 20 -firm & 50 -firm & Herfindahl \\
\hline 20: Food and kindred products & 45.5 & 58.8 & 73.8 & 85.7 & 872.8 \\
21: Tobacco products & 90.4 & 99.2 & 99.9 & 100.0 & 2120.1 \\
22: Textile mill products & 36.6 & 51.3 & 70.8 & 88.1 & 635.6 \\
23: Apparel and other textile products & 29.0 & 39.2 & 54.5 & 70.9 & 486.1 \\
24: Lumber and wood products & 21.4 & 29.9 & 42.3 & 54.8 & 223.5 \\
25: Furniture and fixtures & 29.3 & 40.0 & 54.1 & 68.9 & 405.6 \\
26: Paper and allied products & 36.4 & 53.3 & 74.6 & 88.0 & 590.8 \\
27: Printing and publishing & 21.9 & 31.0 & 43.8 & 56.0 & 305.6 \\
28: Chemicals and allied products & 38.1 & 52.7 & 72.9 & 88.2 & 688.2 \\
29: Petroleum and coal products & 30.3 & 48.8 & 76.8 & 95.4 & 417.9 \\
30: Rubber and miscellaneous plastic products & 21.6 & 30.4 & 41.3 & 53.9 & 318.9 \\
31: Leather and leather products & 41.2 & 57.6 & 78.2 & 92.6 & 740.3 \\
32: Stone clay and glass products & 36.7 & 48.0 & 61.3 & 71.9 & 733.6 \\
33: Primary metal industries & 37.5 & 53.8 & 73.3 & 87.9 & 640.2 \\
34: Fabricated metal products & 26.4 & 34.8 & 47.8 & 61.5 & 387.0 \\
35: Industrial machinery and equipment & 34.8 & 46.3 & 61.6 & 73.2 & 565.0 \\
36: Electronic and other electric equipment & 42.9 & 56.5 & 71.1 & 82.6 & 763.9 \\
37: Transportation equipment & 69.4 & 80.0 & 89.2 & 93.1 & 1979.0 \\
38: Instruments and related products & 37.4 & 50.6 & 68.6 & 82.4 & 724.0 \\
39: Miscellaneous manufacturing industries & 25.8 & 35.5 & 48.9 & 62.2 & 425.8 \\
\hline
\end{tabular}

Notes:

1) Source: Authors' tabulations of 1992 Census of Manufactures Concentration Ratio Series.

2) Each entry is the weighted average of the concentration measure for all the 4-digit SICs in each 2-digit SICs. The weights used are the 4-digit SICs' value of shipments. 


\begin{tabular}{|c|c|c|c|}
\hline \multicolumn{4}{|c|}{$\begin{array}{c}\text { Table 3a } \\
\text { OLS Regressions of Pay-Performance Sensitivity-All Executives } \\
\text { Dependent Variable: Total Compensation }\end{array}$} \\
\hline \multirow[b]{2}{*}{ Regression Coefficients } & \multicolumn{3}{|c|}{ Definition of Rival Firms (SIC level) } \\
\hline & 4-digit & 3-digit & 2-digit \\
\hline Own Performance $\left(\eta_{1}\right)$ & $\begin{array}{c}0.0011 \\
(0.0329)\end{array}$ & $\begin{array}{l}-0.0080 \\
(0.0314)\end{array}$ & $\begin{array}{c}0.0856 \\
(0.0317)\end{array}$ \\
\hline Rival Performance $\left(\eta_{2}\right)$ & $\begin{array}{c}0.3266 \\
(0.0288)\end{array}$ & $\begin{array}{c}0.3586 \\
(0.0296)\end{array}$ & $\begin{array}{c}0.5983 \\
(0.0457)\end{array}$ \\
\hline $\begin{array}{l}\text { Own Performance } x \\
\text { Herf. Percentile }\left(\eta_{3}\right)\end{array}$ & $\begin{array}{c}0.0792 \\
(0.0446)\end{array}$ & $\begin{array}{c}0.1234 \\
(0.0414)\end{array}$ & $\begin{array}{l}-0.0896 \\
(0.0436)\end{array}$ \\
\hline $\begin{array}{l}\text { Rival Performance } x \\
\text { Herf. Percentile }\left(\eta_{4}\right)\end{array}$ & $\begin{array}{l}-0.3410 \\
(0.0393)\end{array}$ & $\begin{array}{l}-0.3928 \\
(0.0422)\end{array}$ & $\begin{array}{l}-0.5044 \\
(0.0514)\end{array}$ \\
\hline Herfindahl Percentile & $\begin{array}{l}380.7444 \\
(69.4374)\end{array}$ & $\begin{array}{l}440.8085 \\
(60.6037)\end{array}$ & $\begin{array}{l}406.8353 \\
(61.4954)\end{array}$ \\
\hline CEO Indicator & $\begin{array}{r}1050.9820 \\
(38.8489)\end{array}$ & $\begin{array}{r}1055.1290 \\
(36.3996)\end{array}$ & $\begin{array}{r}1062.5370 \\
(37.0404)\end{array}$ \\
\hline Adjusted R-squared & 0.1721 & 0.1753 & 0.1822 \\
\hline Number of Observations & 5548 & 6290 & 6451 \\
\hline \multicolumn{4}{|l|}{$\begin{array}{l}\text { Pay-Performance } \\
\text { Sensitivities (Median) }\end{array}$} \\
\hline Own Performance & 0.0407 & 0.0537 & 0.0408 \\
\hline Rival Performance & 0.1561 & 0.1622 & 0.3461 \\
\hline \multicolumn{4}{|l|}{ Test of Bertrand Model } \\
\hline $\begin{array}{l}\text { Herf. Percentile }=0.25 \\
\text { Restriction Value (R) } \\
\text { Test Statistic (W) } \\
\text { P-Value }\end{array}$ & $\begin{array}{r}0.4504 \\
15.4154 \\
0.0001\end{array}$ & $\begin{array}{r}0.6062 \\
36.4833 \\
0.0000\end{array}$ & $\begin{array}{r}-0.0467 \\
0.5445 \\
0.4606\end{array}$ \\
\hline $\begin{array}{l}\text { Herf. Percentile }=0.50 \\
\text { Restriction Value }(\mathrm{R}) \\
\text { Test Statistic }(\mathrm{W}) \\
\text { P-Value }\end{array}$ & $\begin{array}{r}1.0767 \\
11.7095 \\
0.0006\end{array}$ & $\begin{array}{r}1.5622 \\
21.5192 \\
0.0000\end{array}$ & $\begin{array}{r}-0.0870 \\
0.5615 \\
0.4537\end{array}$ \\
\hline $\begin{array}{l}\text { Herf. Percentile }=0.75 \\
\text { Restriction Value }(\mathrm{R}) \\
\text { Test Statistic }(\mathrm{W}) \\
\text { P-Value }\end{array}$ & $\begin{array}{l}5.2245 \\
4.3494 \\
0.0370\end{array}$ & $\begin{array}{r}10.0320 \\
4.0016 \\
0.0455 \\
\end{array}$ & $\begin{array}{r}-0.2151 \\
0.5994 \\
0.4388 \\
\end{array}$ \\
\hline \multicolumn{4}{|c|}{$\begin{array}{l}\text { Notes: } \\
\text { 1) Source: Authors' estimates from ExecuComp and Census of Manufactures datasets. } \\
\text { 2) All dollar values are in thousands (compensation) or millions (performance) of constant } 1994 \text { dollars. } \\
\text { 3) All regressions include dummy variables for 2-digit SIC code, year }(=1994) \text {, and year -SIC interactions. } \\
\text { 4) Standard errors are in parentheses. }\end{array}$} \\
\hline
\end{tabular}




\begin{tabular}{|c|c|c|c|}
\hline \multicolumn{4}{|c|}{$\begin{array}{c}\text { Table 3b } \\
\text { OLS Regressions of Pay-Performance Sensitivity--All Executives } \\
\text { Dependent Variable: Short-Term Compensation }\end{array}$} \\
\hline \multirow[b]{2}{*}{ Regression Coefficients } & \multicolumn{3}{|c|}{ Definition of Rival Firms (SIC level) } \\
\hline & 4-digit & 3-digit & 2-digit \\
\hline Own Performance $\left(\eta_{1}\right)$ & $\begin{array}{c}0.0246 \\
(0.0126)\end{array}$ & $\begin{array}{c}0.0159 \\
(0.0122)\end{array}$ & $\begin{array}{c}0.0250 \\
(0.0117)\end{array}$ \\
\hline Rival Performance $\left(\eta_{2}\right)$ & $\begin{array}{c}0.0775 \\
(0.0111)\end{array}$ & $\begin{array}{c}0.0971 \\
(0.0115)\end{array}$ & $\begin{array}{c}0.2765 \\
(0.0168)\end{array}$ \\
\hline $\begin{array}{l}\text { Own Performance } x \\
\text { Herf. Percentile }\left(\eta_{3}\right)\end{array}$ & $\begin{array}{c}0.0150 \\
(0.0172)\end{array}$ & $\begin{array}{c}0.0319 \\
(0.0161)\end{array}$ & $\begin{array}{l}-0.0220 \\
(0.0161)\end{array}$ \\
\hline $\begin{array}{l}\text { Rival Performance x } \\
\text { Herf. Percentile }\left(\eta_{4}\right)\end{array}$ & $\begin{array}{l}-0.0729 \\
(0.0151)\end{array}$ & $\begin{array}{l}-0.0896 \\
(0.0164)\end{array}$ & $\begin{array}{l}-0.2328 \\
(0.0189)\end{array}$ \\
\hline Herfindahl Percentile & $\begin{array}{l}141.8921 \\
(26.6945)\end{array}$ & $\begin{array}{l}160.4588 \\
(23.5536)\end{array}$ & $\begin{array}{l}170.6416 \\
(22.6366)\end{array}$ \\
\hline CEO Indicator & $\begin{array}{l}490.5205 \\
(14.9351)\end{array}$ & $\begin{array}{l}490.9335 \\
(14.1467)\end{array}$ & $\begin{array}{l}498.9335 \\
(13.6347)\end{array}$ \\
\hline Adjusted R-squared & 0.2135 & 0.2145 & 0.2572 \\
\hline Number of Observations & 5548 & 6290 & 6451 \\
\hline \multicolumn{4}{|l|}{$\begin{array}{l}\text { Pay-Performance } \\
\text { Sensitivities (Median) }\end{array}$} \\
\hline Own Performance & 0.0321 & 0.0319 & 0.0140 \\
\hline Rival Performance & 0.0411 & 0.0523 & 0.1601 \\
\hline \multicolumn{4}{|l|}{ Test of Bertrand Model } \\
\hline $\begin{array}{l}\text { Herf. Percentile }=0.25 \\
\text { Restriction Value (R) } \\
\text { Test Statistic (W) } \\
\text { P-Value }\end{array}$ & $\begin{array}{r}0.8409 \\
14.5693 \\
0.0001\end{array}$ & $\begin{array}{r}0.0104 \\
26.7640 \\
0.0000\end{array}$ & $\begin{array}{r}-0.0057 \\
0.0134 \\
0.9077\end{array}$ \\
\hline $\begin{array}{l}\text { Herf. Percentile }=0.50 \\
\text { Restriction Value }(\mathrm{R}) \\
\text { Test Statistic }(\mathrm{W}) \\
\text { P-Value }\end{array}$ & $\begin{array}{l}1.7534 \\
9.1817 \\
0.0024\end{array}$ & $\begin{array}{r}1.6540 \\
14.8268 \\
0.0001\end{array}$ & $\begin{array}{r}-0.0106 \\
0.0135 \\
0.9076\end{array}$ \\
\hline $\begin{array}{l}\text { Herf. Percentile }=0.75 \\
\text { Restriction Value }(\mathrm{R}) \\
\text { Test Statistic }(\mathrm{W}) \\
\text { P-Value }\end{array}$ & $\begin{array}{l}5.6724 \\
3.1017 \\
0.0782 \\
\end{array}$ & $\begin{array}{l}5.0663 \\
4.3516 \\
0.0370 \\
\end{array}$ & $\begin{array}{r}-0.0261 \\
0.0136 \\
0.9072 \\
\end{array}$ \\
\hline \multicolumn{4}{|c|}{$\begin{array}{l}\text { Notes: } \\
\text { 1) Source: Authors' estimates from ExecuComp and Census of Manufactures datasets. } \\
\text { 2) All dollar values are in thousands (compensation) or millions (performance) of constant } 1994 \text { dollars. } \\
\text { 3) All regressions include dummy variables for 2-digit SIC code, year (=1994), and year -SIC interactions. } \\
\text { 4) Standard errors are in parentheses. }\end{array}$} \\
\hline
\end{tabular}




\begin{tabular}{|c|c|c|c|}
\hline \multicolumn{4}{|c|}{$\begin{array}{c}\text { Table 4a } \\
\text { Median Regressions of Pay-Performance Sensitivity--All Executives } \\
\text { Dependent Variable: Total Compensation }\end{array}$} \\
\hline \multirow[b]{2}{*}{ Regression Coefficients } & \multicolumn{3}{|c|}{ Definition of Rival Firms (SIC level) } \\
\hline & 4-digit & 3-digit & 2-digit \\
\hline Own Performance $\left(\eta_{1}\right)$ & $\begin{array}{c}0.0326 \\
(0.0141)\end{array}$ & $\begin{array}{c}0.0444 \\
(0.0160)\end{array}$ & $\begin{array}{c}0.0181 \\
(0.0134)\end{array}$ \\
\hline Rival Performance $\left(\eta_{2}\right)$ & $\begin{array}{c}0.2312 \\
(0.0119)\end{array}$ & $\begin{array}{c}0.2448 \\
(0.0150)\end{array}$ & $\begin{array}{c}0.6450 \\
(0.0194)\end{array}$ \\
\hline $\begin{array}{l}\text { Own Performance } x \\
\text { Herf. Percentile }\left(\eta_{3}\right)\end{array}$ & $\begin{array}{c}0.1035 \\
(0.0192)\end{array}$ & $\begin{array}{c}0.0634 \\
(0.0211)\end{array}$ & $\begin{array}{c}0.0385 \\
(0.0184)\end{array}$ \\
\hline $\begin{array}{l}\text { Rival Performance } x \\
\text { Herf. Percentile }\left(\eta_{4}\right)\end{array}$ & $\begin{array}{l}-0.2184 \\
(0.0164)\end{array}$ & $\begin{array}{l}-0.1840 \\
(0.0214)\end{array}$ & $\begin{array}{l}-0.5340 \\
(0.0217)\end{array}$ \\
\hline Herfindahl Percentile & $\begin{array}{l}185.9681 \\
(29.7925)\end{array}$ & $\begin{array}{l}218.9738 \\
(30.8268)\end{array}$ & $\begin{array}{l}246.9087 \\
(26.0619)\end{array}$ \\
\hline CEO Indicator & $\begin{array}{l}684.0739 \\
(16.7154)\end{array}$ & $\begin{array}{l}676.0314 \\
(18.5105) \\
\end{array}$ & $\begin{array}{l}676.0100 \\
(15.7292)\end{array}$ \\
\hline Pseudo R-squared & 0.1224 & 0.1263 & 0.1457 \\
\hline Number of Observations & 5548 & 6290 & 6451 \\
\hline \multicolumn{4}{|l|}{$\begin{array}{l}\text { Pay-Performance } \\
\text { Sensitivities (Median) }\end{array}$} \\
\hline Own Performance & 0.0844 & 0.0761 & 0.0374 \\
\hline Rival Performance & 0.1220 & 0.1528 & 0.3780 \\
\hline \multicolumn{4}{|l|}{ Test of Bertrand Model } \\
\hline $\begin{array}{l}\text { Herf. Percentile }=0.25 \\
\text { Restriction Value (R) } \\
\text { Test Statistic (W) } \\
\text { P-Value }\end{array}$ & $\begin{array}{r}0.9958 \\
149.4704 \\
0.0000\end{array}$ & $\begin{array}{r}0.5995 \\
60.6188 \\
0.0000\end{array}$ & $\begin{array}{r}0.1328 \\
32.5208 \\
0.0000\end{array}$ \\
\hline $\begin{array}{l}\text { Herf. Percentile }=0.50 \\
\text { Restriction Value }(\mathrm{R}) \\
\text { Test Statistic }(\mathrm{W}) \\
\text { P-Value }\end{array}$ & $\begin{array}{r}2.0867 \\
91.4639 \\
0.0000\end{array}$ & $\begin{array}{r}1.0147 \\
38.9581 \\
0.0000\end{array}$ & $\begin{array}{r}0.2432 \\
30.2827 \\
0.0000\end{array}$ \\
\hline $\begin{array}{l}\text { Herf. Percentile }=0.75 \\
\text { Restriction Value (R) } \\
\text { Test Statistic }(\mathrm{W}) \\
\text { P-Value }\end{array}$ & $\begin{array}{r}6.8376 \\
26.2689 \\
0.0000\end{array}$ & $\begin{array}{r}2.0768 \\
18.1124 \\
0.0000\end{array}$ & $\begin{array}{r}0.5814 \\
25.7950 \\
0.0000\end{array}$ \\
\hline \multicolumn{4}{|c|}{$\begin{array}{l}\text { Notes: } \\
\text { 1) Source: Authors' estimates from ExecuComp and Census of Manufactures datasets. } \\
\text { 2) All dollar values are in thousands (compensation) or millions (performance) of constant } 1994 \text { dollars. } \\
\text { 3) All regressions include dummy variables for 2-digit SIC code, year }(=1994) \text {, and year -SIC interactions. } \\
\text { 4) Standard errors are in parentheses. }\end{array}$} \\
\hline
\end{tabular}




\begin{tabular}{|c|c|c|c|}
\hline \multicolumn{4}{|c|}{$\begin{array}{c}\text { Table } 4 \mathrm{~b} \\
\text { Median Regressions of Pay-Performance Sensitivity--All Executives } \\
\text { Dependent Variable: Short-Term Compensation }\end{array}$} \\
\hline \multirow[b]{2}{*}{ Regression Coefficients } & \multicolumn{3}{|c|}{ Definition of Rival Firms (SIC level) } \\
\hline & 4-digit & 3-digit & 2-digit \\
\hline Own Performance $\left(\eta_{1}\right)$ & $\begin{array}{c}0.0430 \\
(0.0078)\end{array}$ & $\begin{array}{c}0.0395 \\
(0.0058)\end{array}$ & $\begin{array}{c}0.0070 \\
(0.0060)\end{array}$ \\
\hline Rival Performance $\left(\eta_{2}\right)$ & $\begin{array}{c}0.0820 \\
(0.0068)\end{array}$ & $\begin{array}{c}0.1083 \\
(0.0055)\end{array}$ & $\begin{array}{c}0.3780 \\
(0.0087)\end{array}$ \\
\hline $\begin{array}{l}\text { Own Performance } x \\
\text { Herf. Percentile }\left(\eta_{3}\right)\end{array}$ & $\begin{array}{c}0.0262 \\
(0.0105)\end{array}$ & $\begin{array}{c}0.0140 \\
(0.0076)\end{array}$ & $\begin{array}{c}0.0190 \\
(0.0083)\end{array}$ \\
\hline $\begin{array}{l}\text { Rival Performance } x \\
\text { Herf. Percentile }\left(\eta_{4}\right)\end{array}$ & $\begin{array}{l}-0.0601 \\
(0.0093)\end{array}$ & $\begin{array}{l}-0.0682 \\
(0.0078)\end{array}$ & $\begin{array}{l}-0.3202 \\
(0.0098)\end{array}$ \\
\hline Herfindahl Percentile & $\begin{array}{c}53.5549 \\
(16.5096)\end{array}$ & $\begin{array}{c}94.1495 \\
(11.2027)\end{array}$ & $\begin{array}{l}140.7327 \\
(11.7072)\end{array}$ \\
\hline CEO Indicator & $\begin{array}{c}365.9972 \\
(9.2414) \\
\end{array}$ & $\begin{array}{r}375.0572 \\
(6.7386)\end{array}$ & $\begin{array}{r}379.3934 \\
(7.0599)\end{array}$ \\
\hline Pseudo R-squared & 0.1504 & 0.1537 & 0.1880 \\
\hline Number of Observations & 5548 & 6290 & 6451 \\
\hline \multicolumn{4}{|l|}{$\begin{array}{l}\text { Pay-Performance } \\
\text { Sensitivities (Median) }\end{array}$} \\
\hline Own Performance & 0.0561 & 0.0465 & 0.0165 \\
\hline Rival Performance & 0.0520 & 0.0742 & 0.2179 \\
\hline \multicolumn{4}{|l|}{ Test of Bertrand Model } \\
\hline $\begin{array}{l}\text { Herf. Percentile }=0.25 \\
\text { Restriction Value }(\mathrm{R}) \\
\text { Test Statistic (W) } \\
\text { P-Value }\end{array}$ & $\begin{array}{r}1.0543 \\
60.6770 \\
0.0000\end{array}$ & $\begin{array}{r}0.5050 \\
51.8517 \\
0.0000\end{array}$ & $\begin{array}{r}0.1064 \\
35.9514 \\
0.0000\end{array}$ \\
\hline $\begin{array}{l}\text { Herf. Percentile }=0.50 \\
\text { Restriction Value }(\mathrm{R}) \\
\text { Test Statistic }(\mathrm{W}) \\
\text { P-Value }\end{array}$ & $\begin{array}{r}1.7523 \\
35.7868 \\
0.0000\end{array}$ & $\begin{array}{r}0.7639 \\
35.8187 \\
0.0000\end{array}$ & $\begin{array}{r}0.1989 \\
33.8907 \\
0.0000\end{array}$ \\
\hline $\begin{array}{l}\text { Herf. Percentile }=0.75 \\
\text { Restriction Value }(\mathrm{R}) \\
\text { Test Statistic }(\mathrm{W}) \\
\text { P-Value }\end{array}$ & $\begin{array}{r}3.4681 \\
15.0339 \\
0.0001 \\
\end{array}$ & $\begin{array}{r}1.2881 \\
20.8462 \\
0.0000 \\
\end{array}$ & $\begin{array}{r}0.4969 \\
29.6171 \\
0.0000 \\
\end{array}$ \\
\hline \multicolumn{4}{|c|}{$\begin{array}{l}\text { Notes: } \\
\text { 1) Source: Authors' estimates from ExecuComp and Census of Manufactures datasets. } \\
\text { 2) All dollar values are in thousands (compensation) or millions (performance) of constant } 1994 \text { dollars. } \\
\text { 3) All regressions include dummy variables for 2-digit SIC code, year }(=1994) \text {, and year -SIC interactions. } \\
\text { 4) Standard errors are in parentheses. }\end{array}$} \\
\hline
\end{tabular}


Table 5a

OLS Regressions of Pay-Performance Sensitivity--Just CEOs Dependent Variable: Total Compensation

\begin{tabular}{|c|c|c|c|}
\hline \multirow[b]{2}{*}{ Regression Coefficients } & \multicolumn{3}{|c|}{ Definition of Rival Firms (SIC level) } \\
\hline & 4-digit & 3-digit & 2-digit \\
\hline Own Performance $\left(\eta_{1}\right)$ & $\begin{array}{l}-0.0887 \\
(0.1467)\end{array}$ & $\begin{array}{l}-0.0749 \\
(0.1397)\end{array}$ & $\begin{array}{c}0.1872 \\
(0.1374)\end{array}$ \\
\hline Rival Performance $\left(\eta_{2}\right)$ & $\begin{array}{c}0.9173 \\
(0.1248)\end{array}$ & $\begin{array}{c}0.9728 \\
(0.1293)\end{array}$ & $\begin{array}{c}1.4649 \\
(0.2055)\end{array}$ \\
\hline $\begin{array}{l}\text { Own Performance } x \\
\text { Herf. Percentile }\left(\eta_{3}\right)\end{array}$ & $\begin{array}{c}0.2394 \\
(0.1961)\end{array}$ & $\begin{array}{c}0.3597 \\
(0.1839)\end{array}$ & $\begin{array}{l}-0.2554 \\
(0.1842)\end{array}$ \\
\hline $\begin{array}{l}\text { Rival Performance } x \\
\text { Herf. Percentile }\left(\eta_{4}\right)\end{array}$ & $\begin{array}{l}-1.0279 \\
(0.1731)\end{array}$ & $\begin{array}{l}-1.1769 \\
(0.1847)\end{array}$ & $\begin{array}{l}-1.2262 \\
(0.2269)\end{array}$ \\
\hline Herfindahl Percentile & $\begin{array}{r}782.5208 \\
(287.6328) \\
\end{array}$ & $\begin{array}{c}907.4696 \\
(250.3627) \\
\end{array}$ & $\begin{array}{r}833.5662 \\
(249.4382) \\
\end{array}$ \\
\hline Adjusted R-squared & 0.0887 & 0.0934 & 0.1103 \\
\hline Number of Observations & 1075 & 1223 & 1252 \\
\hline \multicolumn{4}{|l|}{$\begin{array}{l}\text { Pay-Performance } \\
\text { Sensitivities (Median) }\end{array}$} \\
\hline Own Performance & 0.0310 & 0.1050 & 0.0595 \\
\hline Rival Performance & 0.4034 & 0.3844 & 0.8518 \\
\hline \multicolumn{4}{|l|}{ Test of Bertrand Model } \\
\hline $\begin{array}{l}\text { Herf. Percentile }=0.25 \\
\text { Restriction Value }(\mathrm{R}) \\
\text { Test Statistic }(\mathrm{W}) \\
\text { P-Value }\end{array}$ & $\begin{array}{l}0.2945 \\
2.9795 \\
0.0843\end{array}$ & $\begin{array}{r}0.5683 \\
10.8127 \\
0.0010\end{array}$ & $\begin{array}{r}-0.1077 \\
1.0363 \\
0.3087\end{array}$ \\
\hline $\begin{array}{l}\text { Herf. Percentile }=0.50 \\
\text { Restriction Value }(\mathrm{R}) \\
\text { Test Statistic (W) } \\
\text { P-Value }\end{array}$ & $\begin{array}{l}0.7894 \\
2.3176 \\
0.1279\end{array}$ & $\begin{array}{l}1.7715 \\
5.8648 \\
0.0154\end{array}$ & $\begin{array}{r}-0.1992 \\
1.1175 \\
0.2905\end{array}$ \\
\hline $\begin{array}{l}\text { Herf. Percentile }=0.75 \\
\text { Restriction Value }(R) \\
\text { Test Statistic }(W) \\
\text { P-Value }\end{array}$ & $\begin{array}{l}5.9927 \\
0.7985 \\
0.3715\end{array}$ & $\begin{array}{r}32.2210 \\
0.4554 \\
0.4998 \\
\end{array}$ & $\begin{array}{r}-0.4862 \\
1.3056 \\
0.2532 \\
\end{array}$ \\
\hline $\begin{array}{l}\text { Notes: } \\
\text { 1) Source: Authors' estir } \\
\text { 2) All dollar values are ir } \\
\text { 3) All regressions include } \\
\text { 4) Standard errors are in }\end{array}$ & $\begin{array}{l}\text { ExecuCom } \\
\text { is (compensa } \\
\text { variables for } \\
\text { es. }\end{array}$ & $\begin{array}{l}\text { f Manufactur } \\
\text { s (performan } \\
\text { le, year }(=19\end{array}$ & $\begin{array}{l}1994 \text { dollars. } \\
\text {-SIC interactions. }\end{array}$ \\
\hline
\end{tabular}




\begin{tabular}{|c|c|c|c|}
\hline \multicolumn{4}{|c|}{$\begin{array}{c}\text { Table } 5 \mathrm{~b} \\
\text { OLS Regressions of Pay-Performance Sensitivity--Just CEOs } \\
\text { Dependent Variable: Short-Term Compensation }\end{array}$} \\
\hline \multirow[b]{2}{*}{ Regression Coefficients } & \multicolumn{3}{|c|}{ Definition of Rival Firms (SIC level) } \\
\hline & 4-digit & 3-digit & 2-digit \\
\hline Own Performance $\left(\eta_{1}\right)$ & $\begin{array}{c}0.0444 \\
(0.0561)\end{array}$ & $\begin{array}{c}0.0154 \\
(0.0533)\end{array}$ & $\begin{array}{c}0.0354 \\
(0.0502)\end{array}$ \\
\hline Rival Performance $\left(\eta_{2}\right)$ & $\begin{array}{c}0.1513 \\
(0.0477)\end{array}$ & $\begin{array}{c}0.2244 \\
(0.0493)\end{array}$ & $\begin{array}{c}0.6117 \\
(0.0750)\end{array}$ \\
\hline $\begin{array}{l}\text { Own Performance } x \\
\text { Herf. Percentile }\left(\eta_{3}\right)\end{array}$ & $\begin{array}{c}0.0495 \\
(0.0750)\end{array}$ & $\begin{array}{c}0.1096 \\
(0.0701)\end{array}$ & $\begin{array}{l}-0.0358 \\
(0.0673)\end{array}$ \\
\hline $\begin{array}{l}\text { Rival Performance } x \\
\text { Herf. Percentile }\left(\eta_{4}\right)\end{array}$ & $\begin{array}{l}-0.1696 \\
(0.0662)\end{array}$ & $\begin{array}{l}-0.2650 \\
(0.0705)\end{array}$ & $\begin{array}{l}-0.5117 \\
(0.0829)\end{array}$ \\
\hline Herfindahl Percentile & $\begin{array}{c}248.5546 \\
(109.9891)\end{array}$ & $\begin{array}{l}286.1645 \\
(95.4908)\end{array}$ & $\begin{array}{l}308.5381 \\
(91.1006)\end{array}$ \\
\hline Adjusted R-squared & 0.0553 & 0.0670 & 0.1338 \\
\hline Number of Observations & 1075 & 1223 & 1252 \\
\hline \multicolumn{4}{|l|}{$\begin{array}{l}\text { Pay-Performance } \\
\text { Sensitivities (Median) }\end{array}$} \\
\hline Own Performance & 0.0692 & 0.0702 & 0.0175 \\
\hline Rival Performance & 0.0665 & 0.0919 & 0.3559 \\
\hline \multicolumn{4}{|l|}{ Test of Bertrand Model } \\
\hline $\begin{array}{l}\text { Herf. Percentile }=0.25 \\
\text { Restriction Value (R) } \\
\text { Test Statistic }(\mathrm{W}) \\
\text { P-Value }\end{array}$ & $\begin{array}{l}1.2652 \\
3.7981 \\
0.0513\end{array}$ & $\begin{array}{l}1.1464 \\
8.8535 \\
0.0035\end{array}$ & $\begin{array}{r}-0.0161 \\
0.0336 \\
0.8546\end{array}$ \\
\hline $\begin{array}{l}\text { Herf. Percentile }=0.50 \\
\text { Restriction Value (R) } \\
\text { Test Statistic (W) } \\
\text { P-Value }\end{array}$ & $\begin{array}{l}3.3912 \\
1.8797 \\
0.1704\end{array}$ & $\begin{array}{l}3.3962 \\
3.6486 \\
0.0561\end{array}$ & $\begin{array}{r}-0.0298 \\
0.0339 \\
0.8538\end{array}$ \\
\hline $\begin{array}{l}\text { Herf. Percentile }=0.75 \\
\text { Restriction Value }(\mathrm{R}) \\
\text { Test Statistic (W) } \\
\text { P-Value }\end{array}$ & $\begin{array}{r}25.7655 \\
0.2608 \\
0.6096\end{array}$ & $\begin{array}{r}43.6778 \\
0.2666 \\
0.0656\end{array}$ & $\begin{array}{r}-0.0726 \\
0.0347 \\
0.8522\end{array}$ \\
\hline $\begin{array}{l}\text { Notes: } \\
\text { 1) Source: Authors' estin } \\
\text { 2) All dollar values are in } \\
\text { 3) All regressions include } \\
\text { 4) Standard errors are in }\end{array}$ & $\begin{array}{l}\text { ExecuCom } \\
\text { is (compensa } \\
\text { variables for } \\
\text { es. }\end{array}$ & $\begin{array}{l}\text { Manufactur } \\
\text { (performan } \\
\text {, year }(=199\end{array}$ & $\begin{array}{l}1994 \text { dollars. } \\
\text { IC interactions. }\end{array}$ \\
\hline
\end{tabular}




\begin{tabular}{|c|c|c|c|}
\hline \multicolumn{4}{|c|}{$\begin{array}{c}\text { Table } 6 \mathrm{a} \\
\text { Median Regressions of Pay-Performance Sensitivity--Just CEOs } \\
\text { Dependent Variable: Total Compensation }\end{array}$} \\
\hline \multirow[b]{2}{*}{ Regression Coefficients } & \multicolumn{3}{|c|}{ Definition of Rival Firms (SIC level) } \\
\hline & 4-digit & 3-digit & 2-digit \\
\hline Own Performance $\left(\eta_{1}\right)$ & $\begin{array}{l}-0.1392 \\
(0.0897)\end{array}$ & $\begin{array}{l}-0.1788 \\
(0.0798)\end{array}$ & $\begin{array}{c}0.2972 \\
(0.0816)\end{array}$ \\
\hline Rival Performance $\left(\eta_{2}\right)$ & $\begin{array}{c}0.9277 \\
(0.0627)\end{array}$ & $\begin{array}{c}0.9311 \\
(0.0588)\end{array}$ & $\begin{array}{c}1.4945 \\
(0.1222)\end{array}$ \\
\hline $\begin{array}{l}\text { Own Performance } x \\
\text { Herf. Percentile }\left(\eta_{3}\right)\end{array}$ & $\begin{array}{c}0.4233 \\
(0.1184)\end{array}$ & $\begin{array}{c}0.5065 \\
(0.1063)\end{array}$ & $\begin{array}{l}-0.4504 \\
(0.1060)\end{array}$ \\
\hline $\begin{array}{l}\text { Rival Performance } x \\
\text { Herf. Percentile }\left(\eta_{4}\right)\end{array}$ & $\begin{array}{l}-1.0321 \\
(0.0861)\end{array}$ & $\begin{array}{l}-1.0416 \\
(0.0892)\end{array}$ & $\begin{array}{l}-1.1098 \\
(0.1328)\end{array}$ \\
\hline Herfindahl Percentile & $\begin{array}{c}556.4237 \\
(186.7733)\end{array}$ & $\begin{array}{c}550.0742 \\
(151.1471)\end{array}$ & $\begin{array}{c}507.2946 \\
(150.8538)\end{array}$ \\
\hline Pseudo R-squared & 0.0810 & 0.0846 & 0.1122 \\
\hline Number of Observations & 1075 & 1223 & 1252 \\
\hline \multicolumn{4}{|l|}{$\begin{array}{l}\text { Pay-Performance } \\
\text { Sensitivities (Median) }\end{array}$} \\
\hline Own Performance & 0.0725 & 0.0745 & 0.0720 \\
\hline Rival Performance & 0.4117 & 0.4103 & 0.9396 \\
\hline \multicolumn{4}{|l|}{ Test of Bertrand Model } \\
\hline $\begin{array}{l}\text { Herf. Percentile }=0.25 \\
\text { Restriction Value (R) } \\
\text { Test Statistic (W) } \\
\text { P-Value }\end{array}$ & $\begin{array}{r}0.5552 \\
26.7698 \\
0.0000\end{array}$ & $\begin{array}{r}0.6345 \\
44.0755 \\
0.0000\end{array}$ & $\begin{array}{r}-0.2318 \\
12.7968 \\
0.0003\end{array}$ \\
\hline $\begin{array}{l}\text { Herf. Percentile }=0.50 \\
\text { Restriction Value (R) } \\
\text { Test Statistic (W) } \\
\text { P-Value }\end{array}$ & $\begin{array}{r}1.4693 \\
17.5853 \\
0.0000\end{array}$ & $\begin{array}{r}1.6957 \\
22.6238 \\
0.0000\end{array}$ & $\begin{array}{r}-0.3889 \\
14.9636 \\
0.0001\end{array}$ \\
\hline $\begin{array}{l}\text { Herf. Percentile }=0.75 \\
\text { Restriction Value }(\mathrm{R}) \\
\text { Test Statistic (W) } \\
\text { P-Value }\end{array}$ & $\begin{array}{r}10.5504 \\
3.9016 \\
0.0482 \\
\end{array}$ & $\begin{array}{r}12.7090 \\
3.2564 \\
0.0711 \\
\end{array}$ & $\begin{array}{r}-0.7831 \\
19.4778 \\
0.0000\end{array}$ \\
\hline \multicolumn{4}{|c|}{$\begin{array}{l}\text { Notes: } \\
\text { 1) Source: Authors' estimates from ExecuComp and Census of Manufactures datasets. } \\
\text { 2) All dollar values are in thousands (compensation) or millions (performance) of constant } 1994 \text { dollars. } \\
\text { 3) All regressions include dummy variables for 2-digit SIC code, year }(=1994) \text {, and year -SIC interactions. } \\
\text { 4) Standard errors are in parentheses. }\end{array}$} \\
\hline
\end{tabular}




\begin{tabular}{|c|c|c|c|}
\hline \multicolumn{4}{|c|}{$\begin{array}{c}\text { Table } 6 \mathrm{~b} \\
\text { Median Regressions of Pay-Performance Sensitivity--Just CEOs } \\
\text { Dependent Variable: Short-Term Compensation }\end{array}$} \\
\hline \multirow[b]{2}{*}{ Regression Coefficients } & \multicolumn{3}{|c|}{ Definition of Rival Firms (SIC level) } \\
\hline & 4-digit & 3-digit & 2-digit \\
\hline Own Performance $\left(\eta_{1}\right)$ & $\begin{array}{c}0.0386 \\
(0.0337)\end{array}$ & $\begin{array}{c}0.0428 \\
(0.0286)\end{array}$ & $\begin{array}{c}0.0015 \\
(0.0255)\end{array}$ \\
\hline Rival Performance $\left(\eta_{2}\right)$ & $\begin{array}{c}0.2383 \\
(0.0281)\end{array}$ & $\begin{array}{c}0.2869 \\
(0.0268)\end{array}$ & $\begin{array}{c}0.8318 \\
(0.0389)\end{array}$ \\
\hline $\begin{array}{l}\text { Own Performance } x \\
\text { Herf. Percentile }\left(\eta_{3}\right)\end{array}$ & $\begin{array}{c}0.0941 \\
(0.0452)\end{array}$ & $\begin{array}{c}0.0852 \\
(0.0378)\end{array}$ & $\begin{array}{c}0.0448 \\
(0.0342)\end{array}$ \\
\hline $\begin{array}{l}\text { Rival Performance x } \\
\text { Herf. Percentile }\left(\eta_{4}\right)\end{array}$ & $\begin{array}{l}-0.2206 \\
(0.0394)\end{array}$ & $\begin{array}{l}-0.2620 \\
(0.0379)\end{array}$ & $\begin{array}{l}-0.7161 \\
(0.0430)\end{array}$ \\
\hline Herfindahl Percentile & $\begin{array}{l}178.7747 \\
(66.7151) \\
\end{array}$ & $\begin{array}{l}191.9988 \\
(51.6181)\end{array}$ & $\begin{array}{l}316.8628 \\
(46.6178)\end{array}$ \\
\hline Pseudo R-squared & 0.0859 & 0.0942 & 0.1459 \\
\hline Number of Observations & 1075 & 1223 & 1252 \\
\hline $\begin{array}{l}\text { Pay-Performance } \\
\text { Sensitivities (Median) }\end{array}$ & & & \\
\hline Own Performance & 0.0857 & 0.0854 & 0.0239 \\
\hline Rival Performance & 0.1280 & 0.1559 & 0.4738 \\
\hline Test of Bertrand Model & & & \\
\hline $\begin{array}{l}\text { Herf. Percentile }=0.25 \\
\text { Restriction Value }(\mathrm{R}) \\
\text { Test Statistic (W) } \\
\text { P-Value }\end{array}$ & $\begin{array}{r}0.9228 \\
25.2641 \\
0.0000\end{array}$ & $\begin{array}{r}0.7274 \\
34.1367 \\
0.0000\end{array}$ & $\begin{array}{l}0.0900 \\
8.0005 \\
0.0047\end{array}$ \\
\hline $\begin{array}{l}\text { Herf. Percentile }=0.50 \\
\text { Restriction Value (R) } \\
\text { Test Statistic (W) } \\
\text { P-Value }\end{array}$ & $\begin{array}{r}1.8898 \\
14.3681 \\
0.0002\end{array}$ & $\begin{array}{r}1.4669 \\
19.1068 \\
0.0000\end{array}$ & $\begin{array}{l}0.1708 \\
7.5615 \\
0.0060\end{array}$ \\
\hline $\begin{array}{l}\text { Herf. Percentile }=0.75 \\
\text { Restriction Value }(\mathrm{R}) \\
\text { Test Statistic (W) } \\
\text { P-Value }\end{array}$ & $\begin{array}{l}5.8376 \\
4.4410 \\
0.0351\end{array}$ & $\begin{array}{l}4.3612 \\
6.2163 \\
0.0127\end{array}$ & $\begin{array}{l}0.4414 \\
6.6364 \\
0.0100\end{array}$ \\
\hline \multicolumn{4}{|c|}{$\begin{array}{l}\text { Notes: } \\
\text { 1) Source: Authors' estimates from ExecuComp and Census of Manufactures datasets. } \\
\text { 2) All dollar values are in thousands (compensation) or millions (performance) of constant } 1994 \text { dollars. } \\
\text { 3) All regressions include dummy variables for 2-digit SIC code, year }(=1994) \text {, and year -SIC interactions. } \\
\text { 4) Standard errors are in parentheses. }\end{array}$} \\
\hline
\end{tabular}




\begin{tabular}{|c|c|c|c|c|}
\hline \multicolumn{5}{|c|}{$\begin{array}{c}\text { Table } 7 \\
\text { OLS Regressions of Pay-Performance Sensitivity by Inside Ownership--All Executives } \\
\text { Dependent Variable: Total Compensation }\end{array}$} \\
\hline \multirow[b]{2}{*}{ Regression Coefficients } & \multicolumn{2}{|c|}{ Rival Definition is 4-digit SIC } & \multicolumn{2}{|c|}{ Rival Definition is 3-digit SIC } \\
\hline & Low Ownership & High Ownership & Low Ownership & High Ownership \\
\hline Own Performance $\left(\eta_{1}\right)$ & $\begin{array}{c}0.1036 \\
(0.0299)\end{array}$ & $\begin{array}{l}-0.0267 \\
(0.0566)\end{array}$ & $\begin{array}{c}0.0984 \\
(0.0297)\end{array}$ & $\begin{array}{l}-0.0499 \\
(0.0541)\end{array}$ \\
\hline Rival Performance $\left(\eta_{2}\right)$ & $\begin{array}{c}0.1053 \\
(0.0243)\end{array}$ & $\begin{array}{c}0.4394 \\
(0.0548)\end{array}$ & $\begin{array}{c}0.1363 \\
(0.0259)\end{array}$ & $\begin{array}{c}0.4834 \\
(0.0555)\end{array}$ \\
\hline $\begin{array}{l}\text { Own Performance } x \\
\text { Herf. Percentile }\left(\eta_{3}\right)\end{array}$ & $\begin{array}{l}-0.0249 \\
(0.0408)\end{array}$ & $\begin{array}{c}0.0967 \\
(0.0763)\end{array}$ & $\begin{array}{l}-0.0197 \\
(0.0391)\end{array}$ & $\begin{array}{c}0.1811 \\
(0.0710)\end{array}$ \\
\hline $\begin{array}{l}\text { Rival Performance } x \\
\text { Herf. Percentile }\left(\eta_{4}\right)\end{array}$ & $\begin{array}{l}-0.0926 \\
(0.0333)\end{array}$ & $\begin{array}{l}-0.4771 \\
(0.0736)\end{array}$ & $\begin{array}{l}-0.1203 \\
(0.0374)\end{array}$ & $\begin{array}{l}-0.5590 \\
(0.0775)\end{array}$ \\
\hline Herfindahl Percentile & $\begin{array}{l}138.5964 \\
(53.8749)\end{array}$ & $\begin{array}{c}537.3100 \\
(144.7219)\end{array}$ & $\begin{array}{l}241.5123 \\
(50.4860)\end{array}$ & $\begin{array}{c}608.9089 \\
(123.0363)\end{array}$ \\
\hline CEO Indicator & $\begin{array}{l}810.8182 \\
(55.0736) \\
\end{array}$ & $\begin{array}{l}964.9900 \\
(66.3131) \\
\end{array}$ & $\begin{array}{l}818.8994 \\
(53.1970) \\
\end{array}$ & $\begin{array}{l}975.8305 \\
(61.4254) \\
\end{array}$ \\
\hline Adjusted R-squared & 0.1581 & 0.1326 & 0.1532 & 0.1393 \\
\hline Number of Observations & 2461 & 2463 & 2798 & 2799 \\
\hline \multicolumn{5}{|l|}{$\begin{array}{l}\text { Pay-Performance } \\
\text { Sensitivities (Median) }\end{array}$} \\
\hline Own Performance & 0.0911 & 0.0217 & 0.0886 & 0.0407 \\
\hline Rival Performance & 0.0590 & 0.2009 & 0.0761 & 0.2039 \\
\hline \multicolumn{5}{|l|}{ Test of Bertrand Model } \\
\hline $\begin{array}{l}\text { Herf. Percentile }=0.25 \\
\text { Restriction Value }(\mathrm{R}) \\
\text { Test Statistic (W) } \\
\text { P-Value }\end{array}$ & $\begin{array}{l}1.0329 \\
4.3476 \\
0.0371\end{array}$ & $\begin{array}{l}0.2904 \\
4.3940 \\
0.0361\end{array}$ & $\begin{array}{l}0.8123 \\
5.3763 \\
0.0204\end{array}$ & $\begin{array}{r}0.5054 \\
16.8961 \\
0.0000\end{array}$ \\
\hline $\begin{array}{l}\text { Herf. Percentile }=0.50 \\
\text { Restriction Value }(\mathrm{R}) \\
\text { Test Statistic }(\mathrm{W}) \\
\text { P-Value }\end{array}$ & $\begin{array}{l}2.0031 \\
2.6346 \\
0.1046\end{array}$ & $\begin{array}{l}0.7376 \\
3.7177 \\
0.0538\end{array}$ & $\begin{array}{l}1.5809 \\
3.1267 \\
0.0770\end{array}$ & $\begin{array}{r}1.4355 \\
10.6629 \\
0.0011\end{array}$ \\
\hline $\begin{array}{l}\text { Herf. Percentile }=0.75 \\
\text { Restriction Value }(\mathrm{R}) \\
\text { Test Statistic (W) } \\
\text { P-Value }\end{array}$ & $\begin{array}{l}5.4290 \\
1.0526 \\
0.3049 \\
\end{array}$ & $\begin{array}{l}4.4713 \\
1.6512 \\
0.1988 \\
\end{array}$ & $\begin{array}{l}4.3203 \\
1.2023 \\
0.2729 \\
\end{array}$ & $\begin{array}{r}14.5009 \\
1.5121 \\
0.2188 \\
\end{array}$ \\
\hline $\begin{array}{l}\text { Notes: } \\
\text { 1) Source: Authors' esti } \\
\text { 2) All dollar values are } \\
\text { 3) All regressions includ } \\
\text { 4) Standard errors are in }\end{array}$ & $\begin{array}{l}\text { tes from ExecuCor } \\
\text { ousands (compen. } \\
\text { ummy variables fo } \\
\text { rentheses. }\end{array}$ & $\begin{array}{l}\text { and Census of Ma } \\
\text { on) or millions ( } p e \\
\text {-digit SIC code, ye }\end{array}$ & $\begin{array}{l}\text { actures datasets. } \\
\text { mance) of consta } \\
(=1994) \text {, and year }\end{array}$ & $\begin{array}{l}1994 \text { dollars. } \\
\text { SIC interactions. }\end{array}$ \\
\hline
\end{tabular}

